\title{
Massimo Salvatores: integral experiments and their use for the validation of nuclear data and the neutronic design of advanced nuclear systems
}

\author{
Giuseppe Palmiotti ${ }^{1, *}$, Patrick Blaise ${ }^{2}$, and Frédéric Mellier ${ }^{3}$ \\ ${ }^{1}$ Idaho National Laboratory, Nuclear Systems Design and Analysis Division, P.O. Box 1625 Box 1625, Idaho Falls, \\ ID 83415-3860, USA \\ ${ }^{2}$ French Alternatives and Atomic Energies Commission, DES/Scientific Division Energies, CEA-Saclay, 91191 Gif-sur-Yvette, \\ France \\ ${ }^{3}$ French Alternatives and Atomic Energies Commission, DES/IRESNE/Reactor Studies Department, CEA-Cadarache, \\ 13108 Saint Paul-lez-Durance, France
}

Received: 7 January 2021 / Received in final form: 1 April 2021 / Accepted: 8 April 2021

\begin{abstract}
Among the many domains of reactor physics on which Massimo Salvatores gave his considerable contributions, he was particularly passionate about integral experiments. In this paper, we make a review of selected experimental campaigns among the numerous ones he has promoted, conceived, designed, directed, or analyzed. They have been regrouped in a temporal sequence corresponding to the different periods of Massimo's career, which exceeded 50 years. When possible, for each of the experiments we provide a brief description, the goal for which it was conceived and carried out, and the practical impact on validation and design improvement. Finally, the conclusions offer thoughts and suggestions for the future of the integral experiments and a possible way of honoring the invaluable legacy that Massimo Salvatores has left to us.
\end{abstract}

\section{Foreword}

The recent death of Massimo Salvatores has left a big hole not only in the hearts of his family and friends but, also in the large community of reactor physicists, among whom he was so well renowned and revered. He was a giant in the nuclear reactor physics and gave many contributions in the different domains of this discipline. However, in this paper we will focus only on his efforts in the field of integral experiments. The contributions of Massimo Salvatores in this area for the validation of the neutronic design of advanced nuclear systems are countless. He was a passionate advocate of the usefulness of integral experiments. He always saw the experiments as having a pivotal role among the three pillars of the nuclear reactor physics, which also include theory and methods. Some of his visions on the importance of the connection between theory and experiments can be found in his scientific production on the subject $[16,29,48,51,54,55,57,58,62]$. In this paper we will review the contribution he has made in this field.

First, we will summarize methodologies for using the measurements performed in integral experiments for validating nuclear data and the design of advanced nuclear

\footnotetext{
* e-mail: giuseppe.palmiotti@inl.gov
}

systems. Then, considering the enormous amount of integral experiments in which Massimo was involved, we will only discuss the most impactful experiments. We will regroup this in a temporal sequence corresponding to the different periods of Massimo's extensive career (Tab. 1). Whenever possible, for each of the experiments we will provide a brief description, the goal for which it was conceived and carried out, and the practical impact on validation and design improvement.

\section{Methodologies for exploiting integral experiments for neutronics reactor design validation}

Integral experiments are being used from the dawn of the nuclear energy age. In fact, Enrico Fermi himself built 30 subcritical experiments [68] before the CP1 assembly went critical on December 2, 1942. Later, integral experiments were carried out in support of reactor design mainly to compare measurements against the calculations for testing how good were the neutron cross sections used in computing the corresponding values. In the case of mock-up experiments, the notion of a bias factor [69] was derived, and the uncertainty related to neutron cross 
Table 1. Massimo's career (from: "Massimo Salvatores 1941-2020", Giuseppe Palmiotti (INL), Annals of Nuclear Energy 146 (2020) 107633).

\begin{tabular}{|c|c|c|}
\hline Period & Position & $\begin{array}{c}\text { The main programs and projects Massimo } \\
\text { contributed to }\end{array}$ \\
\hline 1963 & doctor with magna cum laude (University of Turin) & \multirow{23}{*}{$\begin{array}{c}\text { PEC reactor project, experiments in TAPIRO } \\
\text { research reactor, PECORE experiments } \\
\text { (MASURCA facility), Experiments in } \\
\text { HARMONIE facility, } \\
\text { ZPR6-7 experiments (ZPPR facility), } \\
\text { NEFERTITI programs in TAPIRO, PROFIL1 \& } 2 \\
\text { and TRAPU irradiations in PHENIX, } \\
\text { PRE-RACINE, RACINE and BALZAC programs } \\
\text { at MASURCA, } \\
\text { Design of SUPERPHENIX, start-up tests, } \\
\text { European collaborative program on EFR } \\
\text { (AGT } 3 \text { on core physics), CONRAD programs } \\
\text { at MASURCA } \\
\text { BERENICE international experimental } \\
\text { benchmark in MASURCA, } \\
\text { CIRANO and COSMO programs (MASURCA), } \\
\text { CAPRA project, GEDEON coordinate project, } \\
\text { EFFTRA collaboration, } \\
\text { MUSE experiment series in MASURCA, } \\
\text { MEGAPIE experiments and project at } \\
\text { PSI/SINQ facility, TRADE experiments at } \\
\text { Casaccia TRIGA, EUROTRANS Euratom } \\
\text { project, } \\
\text { MAny contributions to OCDE/NEA activities } \\
\text { ANC }\end{array}$} \\
\hline 1964 & join CNEN (today ENEA), Casaccia Research Centre & \\
\hline 1964-1977 & CNEN & \\
\hline 1970-1971 & visiting scientist at $A N L$ & \\
\hline 1977 & join CEA, Cadarache Research Centre & \\
\hline $1977-2000$ & CEA & \\
\hline 1983 & head of Physics Studies Laboratory (LEPH) & \\
\hline 1989 & head of Reactor Physics and Fuel Cycle Service (SPRC) & \\
\hline \multirow[b]{2}{*}{1992} & research director & \\
\hline & $\begin{array}{c}\text { program manager for the Fuel Cycle Programs at the CEA Nuclear } \\
\text { Reactor Directorate }\end{array}$ & \\
\hline 1995 & $\begin{array}{c}\text { member of the Scientific Advisory Board of the Energy Department of } \\
\text { the Paul Scherrer Institute }\end{array}$ & \\
\hline 1996 & $\begin{array}{c}\text { co-director of the Research Coordinate Project (CEA, CNRS, EdF, } \\
\text { Framatome) on new options for waste management (GEDEON research } \\
\text { project) }\end{array}$ & \\
\hline 1997 & \begin{tabular}{|} 
member of the Scientific Advisory Board of the Institute for Reference \\
Materials and Measurements (IRMM)
\end{tabular} & \\
\hline 1997 & chairman of the National French Committee for Nuclear Data (CFDN) & \\
\hline 1998 & member of the Scientific Council of CEA & \\
\hline 2001-2002 & visiting scientist at ANL (2001-2002) & \\
\hline 2001-2019 & consulting positions at different organizations & \\
\hline $2001-2014$ & scientific advisor to the director of CEA Nuclear Energy & \\
\hline $2002-2009$ & scientific advisor at ANL & \\
\hline $2002-2010$ & scientific advisor at ENEA & \\
\hline $2002-2010$ & scientific advisor at Karlsrhue Institute of Technology & \\
\hline 2007-2009 & policy director for the Generation-IV International Forum & \\
\hline 2006-2019 & scientific advisor at INL & \\
\hline
\end{tabular}

sections would be significantly reduced, through representativity and transposition concepts [70].

On this subject, Massimo Salvatores co-authored a recent paper [66] that revisits the bias factor methodologies and suggests adopting a methodology allowing obtaining, for a specific target reactor, the same results of an adjustment using the same integral experiments without the need of producing actual adjusted cross sections and related covariance matrices.

One key quantity for assessing the usefulness of an integral experiment with respect to a target reactor is the representativity factor [51]. This quantity was first introduced by Usatchev and Bobkov [70], but it was made popular by a seminal paper by Massimo [16]. This factor makes use of the sandwich formula, but it uses the cross term between the integral experiment and the target reactor for the integral parameter for which the sensitivity coefficients have been computed. This factor can be interpreted as the cosine between the experiment and the target reactor vectors of uncertainties. A representativity factor of zero implies that two systems are orthogonal (i.e., no "information" can be shared), while a value of 1 states that the experiment and the target reactor react in the same way to a change (uncertainty in this instance) of the cross sections. In this case, the experiment is a perfect mock-up of the target reactor.

However, the most efficient use of integral experiments is through a neutron cross-section adjustment (i.e., data assimilation). This method is a Bayesian approach that uses the discrepancies observed in integral experiments between calculations and measurements, in connection with sensitivity coefficients and nuclear data covariance matrices to derive improved central values and minimized new covariance matrices. The solution is obtained through the generalized linear least-square method or an equivalent Lagrange multipliers method applied to the maximum likelihood function (corresponding to the discrepancies obtained between the experiment and the calculation). Massimo has published many papers on this methodology (among them $[7,52,55,58]$ ). It is through his leadership role on the WPEC Subgroup 33 [59], Subgroup 39 [65], and Subgroup 46 that he initiated a younger generation of reactor physicists to the usefulness of this methodology. One important point always enlightened by Massimo is the role of the experimental correlation in the adjustment [62]. Finally, we want to mention that Massimo was one of the 
two proponents of the Consistent Method [76] where the basic nuclear parameters instead of the multigroup cross sections are adjusted [59], [71].

\section{The Italian period (1963-1977)}

\subsection{ZPR6}

Massimo spent 1 year at Argonne National Laboratory (ANL) (between 1971 and 1972) and was partly involved in the analysis of the ZPR6 (Zero Power Reactor) assemblies $[1-4,8]$. Two main aspects were the focus of the analysis, besides the usual study for validating the ENDF/B libraries: heterogeneity and Doppler effects. The heterogeneity investigation was necessary because for the most part, the ZPR (and later ZPPR) assemblies used the plate form for the fuel. While the rodlet form induced a significantly less heterogeneity effect (of the order of a couple of hundreds pcm), this was not the case for the plate form where effects greater than $2000 \mathrm{pcm}$ were sometimes found. This, in turn, required more accurate treatment of the self-shielding effects both in energy and space. Collision probability was mostly employed to correctly generate multigroup cross sections. Regarding the Doppler effect, an accurate integral transport approach, which was derived from a previously proposed bilinear weighting method [72], allowed for better analysis that helped to understand some peculiar results of the measurements of Doppler effects in a fast structure.

\subsection{TAPIRO}

TAPIRO (TAratura PIla Rapida Potenza Zero - Fast Pile Calibration at 0 Power) was the research fast reactor operated at the Casaccia center (close to Rome in Italy) and is still working today. The unique feature of this reactor was the presence of a copper reflector. With the availability of two-dimensional transport code, it was finally possible to develop a credible model of this reactor (see Fig. 1), very small in size (core diameter of $\sim 12 \mathrm{~cm}$ for a height of $\sim 17 \mathrm{~cm}$ ). Massimo was then involved in using the reaction rates measured at the TAPIRO for validating the relevant neutron cross sections $[5,6]$. The validation consisted in testing the most modern library of the time and ENDF/B-III, and some indications were provided for ${ }^{235} \mathrm{U}$ and $\mathrm{Cu}$ cross sections.

\section{Propagation experiments in iron and sodium [10-14]}

The propagation experiments included in this section cover a period that overlaps both the Italian and French periods. The first experiment [10] was the one carried out at the TRIGA reactor of the Casaccia center (see Fig. 2) where the neutrons coming out from the thermal column of the reactor where converted by a fission plate $\left({ }^{235} \mathrm{U} 90 \%\right.$ enriched) to a fast spectrum and then attenuated through a cube of a 1-meter side of iron. The attenuation of several detectors $\left({ }^{197} \mathrm{Au}(\mathrm{n}, \boldsymbol{\gamma}),{ }^{55} \mathrm{Mn}(\mathrm{n}, \boldsymbol{\gamma}),{ }^{235} \mathrm{U}(\mathrm{n}, \mathrm{f})\right.$, and $\left.{ }^{239} \mathrm{Pu}(\mathrm{n}, \mathrm{f})\right)$ were used to test the different version of the iron cross

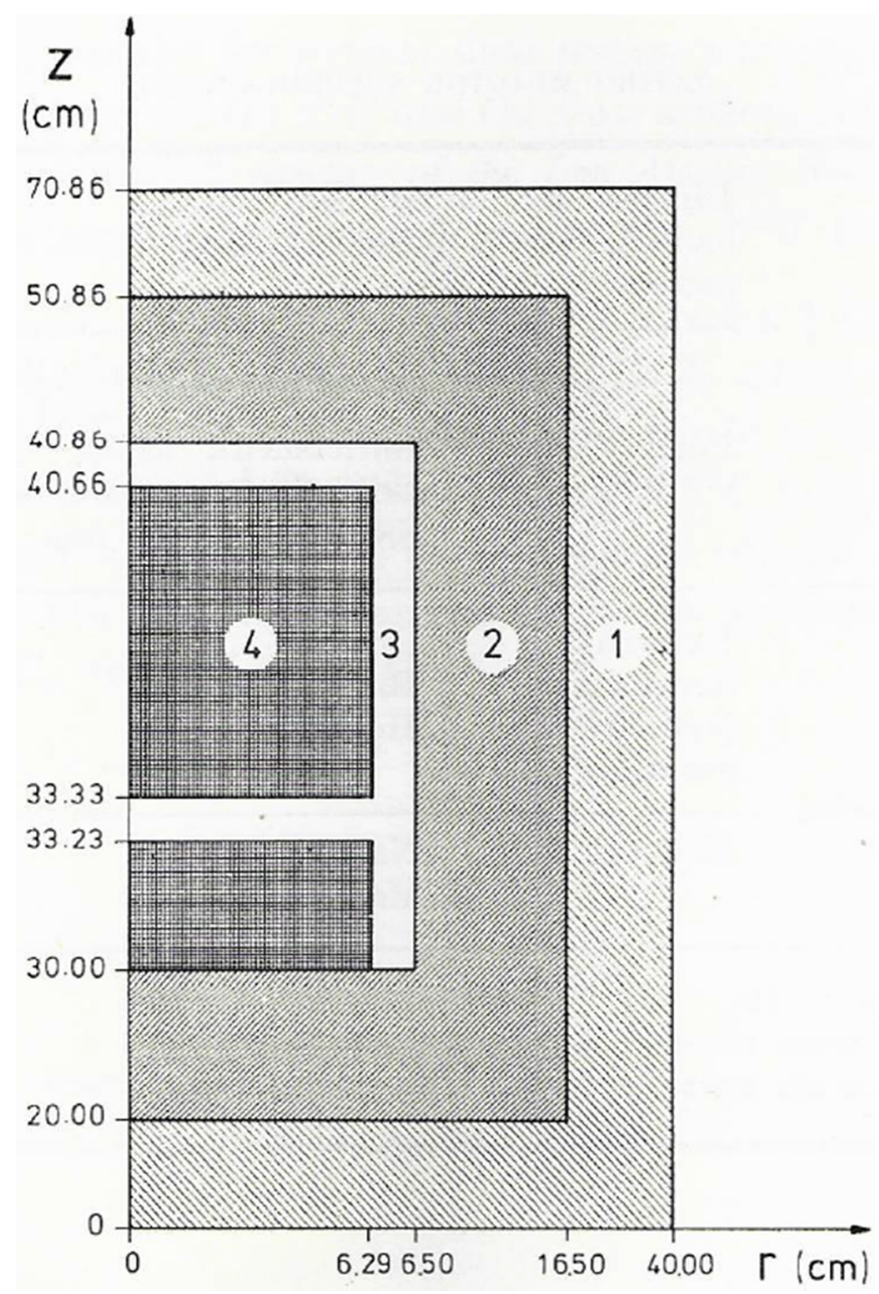

Fig. 1. TAPIRO reactor: two-dimensional model for transport calculations. Regions: (1) reduced density (98\%) Cu reflector; (2) full density $\mathrm{Cu}$ reflector; (3) void; and (4) ${ }^{235} \mathrm{U}$ core $(>90 \%$ enriched).

sections that were present in the ENDF/B libraries of the time. It is interesting to note that the iron data still today are not performing well in similar attenuation problems. One notable observation was made about the overlap of the manganese (a few percent impurity) resonance at $19 \mathrm{keV}$ with the resonance deep (penetration window) at $\sim 25 \mathrm{keV}$ of the iron resonance at $40 \mathrm{keV}$.

Massimo then was involved in the shielding experiments carried out at the HARMONIE reactor located at the French research center of Cadarache. In fact, a series of deep propagation studies were designed and conducted in the HARMONIE reference neutron spectrum. As part of these experimental campaigns, the JASON program enabled the treating of several materials in shielding experiments related to fast reactors applications. Among all materials tested, iron and sodium were thoroughly investigated, together with stainless steel and $\mathrm{B}_{4} \mathrm{C}$ as neutron absorber.

The results of these propagation experiments were then exploited for data testing or adjustment in several papers $[11,12,14]$, and the notable one [13] where the consistent 


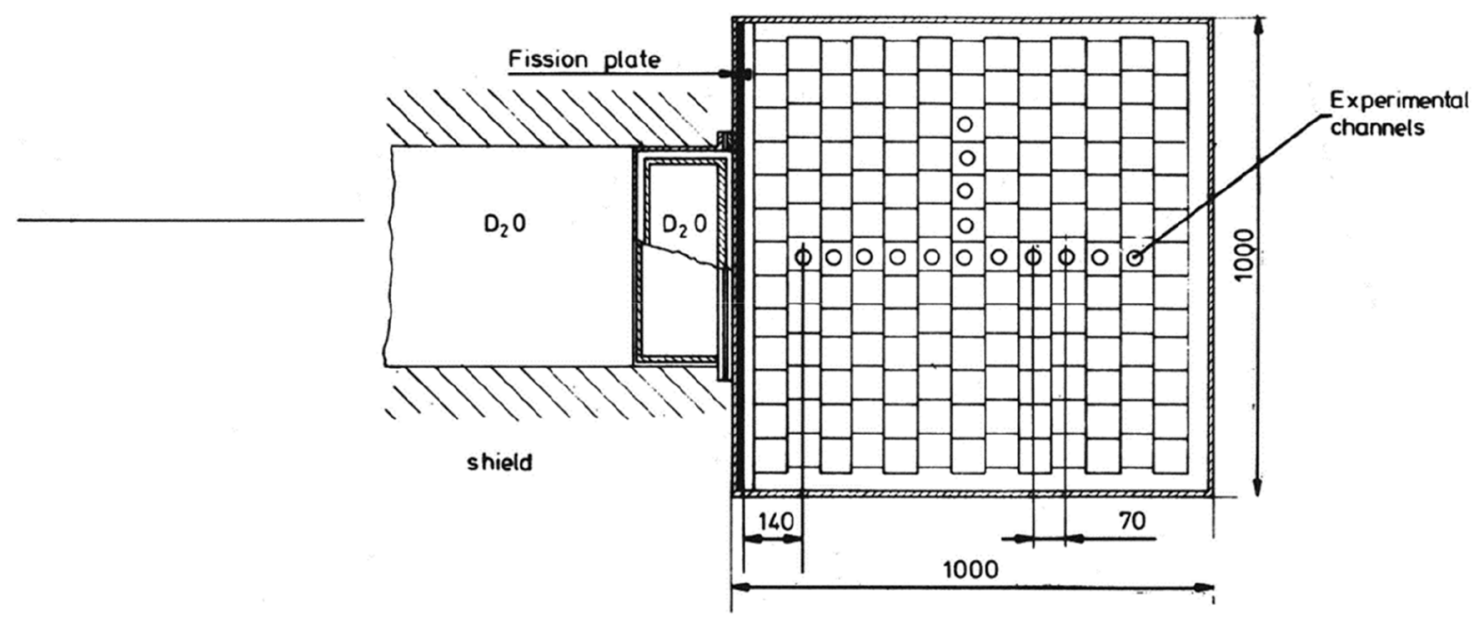

Fig. 2. Schematic diagram of the neutron source and the iron column showing the detector channels (all dimensions in mm).

method [9] for the adjustment of the iron inelastic scattering data (both at the continuous and discrete levels), was demonstrated for the first time.

\section{The French period (1977-2000)}

The French period covers a large amount of major experimental programs mainly led into the MASURCA critical facility at Cadarache [73]. We list hereafter the main achievements of these programs during the 19752000 period.

\subsection{PECORE (1975-1976)}

This program was conducted in the MASURCA critical facility at Cadarache, within the framework of a collaboration with the CNEN (Italian Committee for nuclear energy) for the Prova Elementi di Combustibile - Fuel Element Testing (PEC) reactor project. In the 1970s, Italy was planning to build a nuclear facility for testing nuclear fuels for fast reactors. Unfortunately, the project never materialized, and the PEC experimental reactor was later cancelled; however, the PECORE experimental program in support of its validation was carried out.

As the amount of plutonium available at MASURCA facility was insufficient, the PECORE experiment was conducted by setting up two different fuel zones designed to be similar in terms of neutron energy spectrum. Two core configurations were investigated:

- the PECORE 1 configuration with an internal zone loaded with $\mathrm{UPuO}_{2}$ fuel and an external zone loaded with the $\mathrm{R} 2\left(\mathrm{UO}_{2}\right)$ cell. It simulated the actual environment of the PEC reactor.

- the PECORE 2 configuration with an internal zone loaded with the $\mathrm{R} 2$ cell and an external zone loaded with $\mathrm{UPuO}_{2}$ fuel (so-called ZONA 2 cell, with a Pu content of $25 \%$ ). This configuration was built to study the system of PEC reactor control rods.
While still in Italy, Massimo was involved in some of the design/planning of the experimental configurations and the post-analysis of the experimental results.

\subsection{Fast reactors blankets (1981-1982)}

The experimental campaign NEFERTITI [15] was carried out in 1981-1982 at the TAPIRO reactor. This campaign was part of the joint program CNEN (Italy)-CEA (France) for fast reactors. The response of threshold and continuous activation detectors placed in the simulated blanket region fed by the fast source from the TAPIRO through a buffer fissile zone were analyzed with both diffusion and transport to evaluate their performances (see Fig. 3). The experiment had the purpose of studying blanket properties. In general, good agreement was found for most of the spectral indices except for the threshold one of ${ }^{238} U \sigma_{\mathrm{f}} /{ }^{235} \mathrm{U} \sigma_{\mathrm{f}}$, which is very sensitive to the fast portion of the spectrum.

\subsection{Study of radial heterogeneous cores (1976-1984)}

The PRE-RACINE program (1976-1979) and soon after the RACINE program (1979-1984) were defined for the neutronic study of radial heterogeneous cores. In this concept, fertile subassemblies are inserted in the fissile zone to improve the breeding gain and $\mathrm{Pu}$ amount doubling time.

For PRE-RACINE, relatively simple core geometries were studied: homogenous cores with various fuel composition ( $\mathrm{Pu}$ with $8 \%$ and $18 \%{ }^{240} \mathrm{Pu}$ content) and a configuration with a central fertile island (equivalent radius of $15 \mathrm{~cm}$ ). The experimental program included an extensive series of void sodium measurements with about 30 voided configurations of various radial and axial amplitudes (Fig. 4), in the fuel or in the internal fertile.

The analysis demonstrated that the CARNAVAL IV calculation system correctly predicted the sensitivity of the reactivity effect of the sodium void to the fuel composition $\left({ }^{240} \mathrm{Pu}\right.$ content), but also showed the need to improve the treatment of axial leakage in particular. 


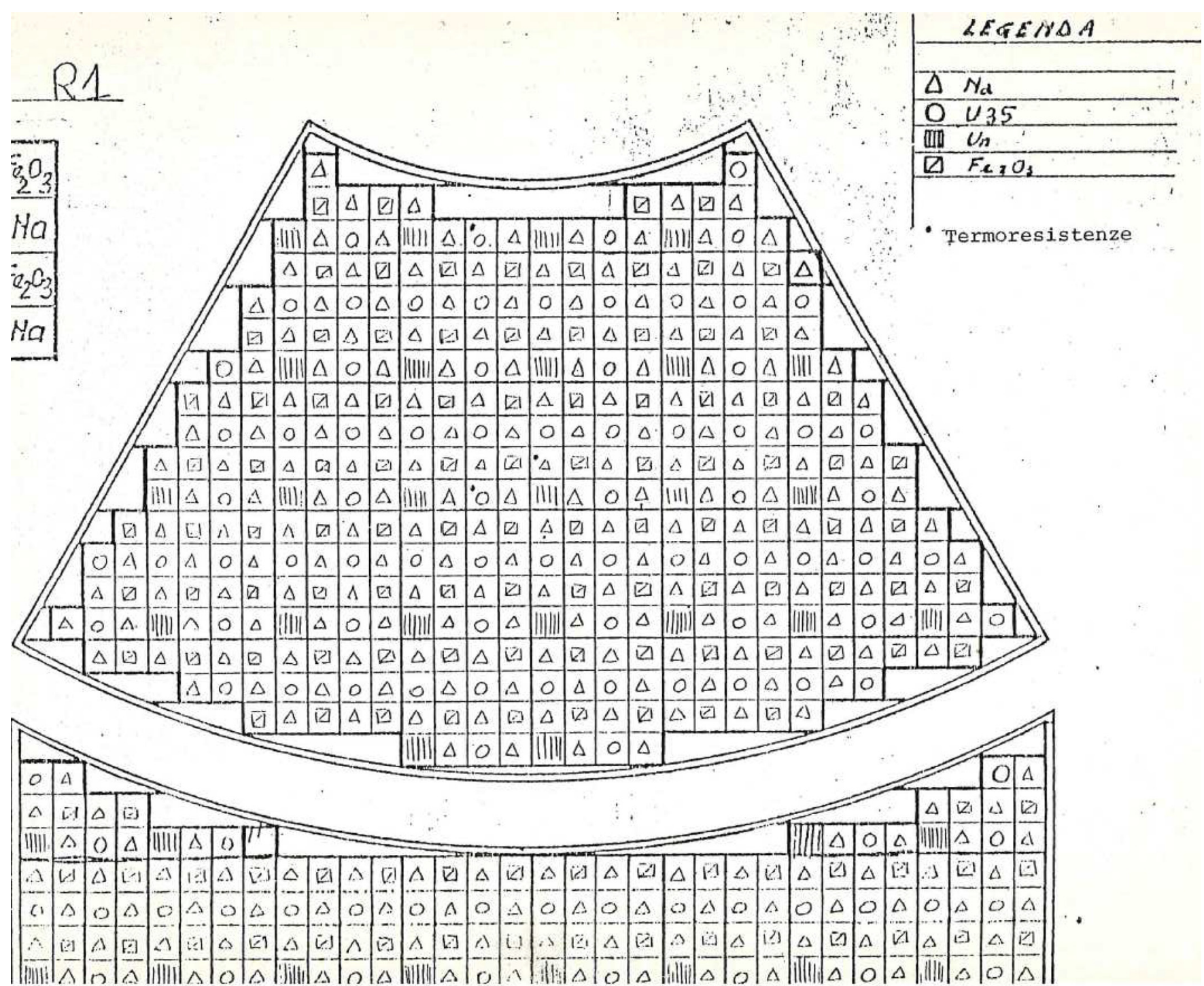

Fig. 3. Buffer zone with fuel and sodium rodlets on the external region of the NEFERTITI configuration at the TAPIRO reactor.

The RACINE program, that came after PRERACINE, was much more ambitious. It is one of the most important conducted at MASURCA both in terms of duration, objectives, and stakes. The major goal of the program was to validate the calculation tools and schemes used for Superphénix studies and to explore, to a certain degree, the physical characteristics and problems of large cores. The experimental program enabled:

- providing the in-depth study of the "radial composite core" concept (RACINE 1A, 1B, 1C, and 1F).

- addressing the questions calculating the efficiency of control rods and interaction problems between rods (RACINE 1D and 1E).

- investigating the technical options taken for the neutron control of Superphénix (the use of neutron guides).

- examining the calculation tool performances and the experimental strategy used for the "checkerboard pattern" subcritical approach selected for loading Superphénix.
The measurements carried out during this program are summarized in Table 2.

The RACINE 1A, 1B, and 1C configurations (see Fig. 5) were aimed at studying different configurations each with a central island and an external fertile ring. In these three configurations, the external ring was positioned differently but its volume remained the same. RACINE $1 F$ was aimed at studying the effects produced by a larger volume fertile ring. This core is one of the largest cores ever built at MASURCA. The external diameter of the fissile zone was approximately $2.2 \mathrm{~m}$.

Two distinct experiments were interested in the calculation and measurement of the reactivity weight of control rods:

- the RACINE 1D experiment that had two configurations: a "clean" reference critical configuration and one with an absorber rod simulated in the core's center.

- the RACINE $1 \mathrm{E}$ experiment for which the goal was to study the problems of interaction between rods. 


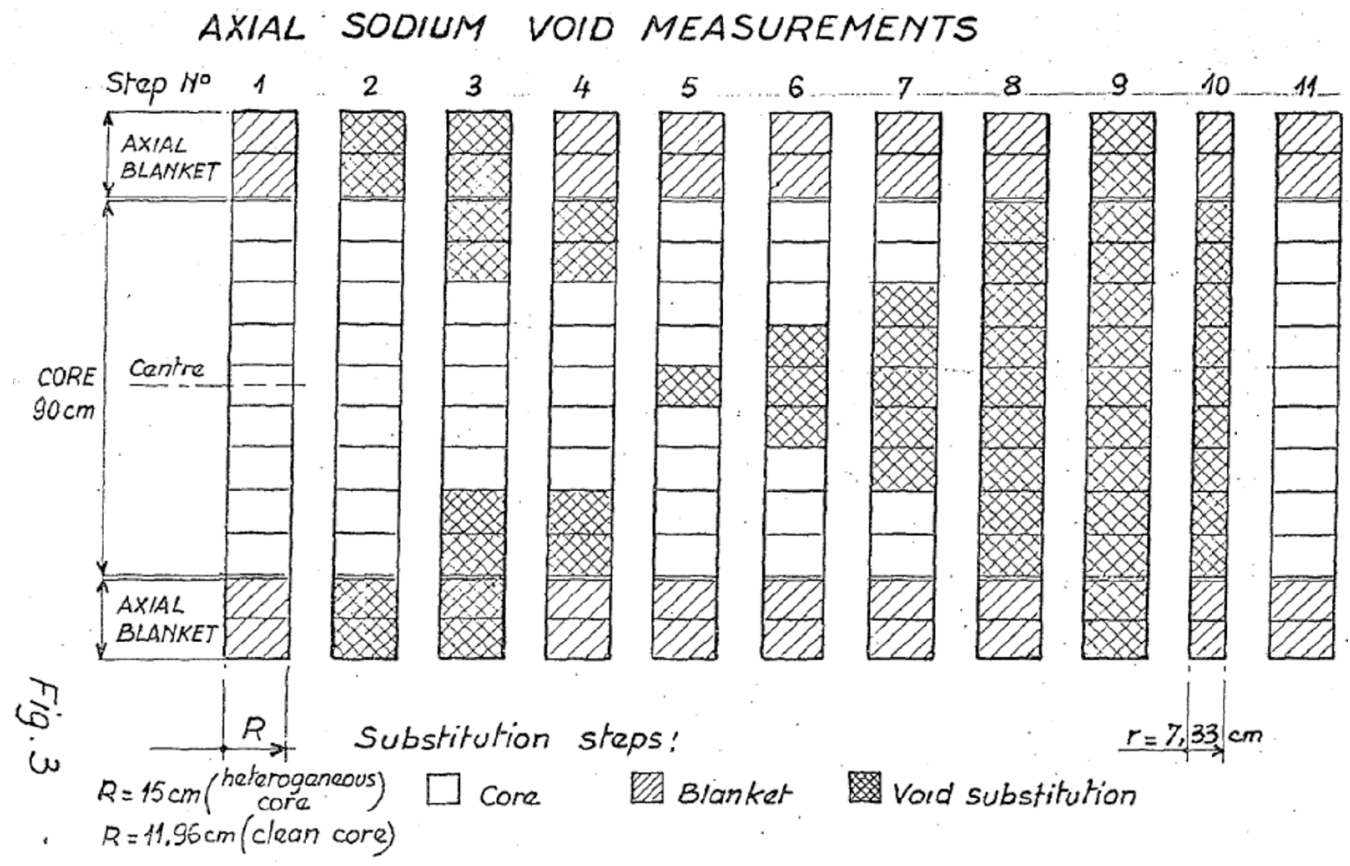

Fig. 4. Axial voided configurations in PRE-RACINE program (from: "Interpretation of sodium void measurements performed in PRE-RACINE programme on MASURCA", F. LYON, M. MARTINI, G. HUMBERT, $21^{\text {st }}$ NEACRP meeting "Fast reactor Physics", November Tokyo, 6-10, 1978).

Table 2. Experiments performed during the RACINE program in MASURCA.

\begin{tabular}{|c|c|c|}
\hline Parameters & Programme phase & Characteristics \\
\hline Reaction rate distribution & $\begin{array}{l}\text { RACINE } 1 \mathrm{~A} \\
\text { RACINE } 1 \mathrm{~B} \\
\text { RACINE } 1 \mathrm{C} \\
\text { RACINE } 1 \mathrm{~F} \\
\text { RACINE } 1 \mathrm{E} \\
\text { RACINE } 1 \mathrm{I}\end{array}$ & $\begin{array}{l}\text { Different fertile ring positions but with the same volume } \\
\text { Increased ring volume } \\
\text { Thicker fertile ring than in RACINE 1A, 1B, and 1C } \\
\text { Measurements close to control rod singularities } \\
\text { IRMA experiment - international benchmark } \\
\text { for reaction rate technique and spectral indices } \\
\text { intercomparisons }\end{array}$ \\
\hline$\gamma$-heating & RACINE $1 \mathrm{~A}$ & Multi-laboratories intercomparison of techniques \\
\hline Control rodworth & $\begin{array}{l}\text { RACINE 1D } \\
\text { RACINE 1E } \\
\text { RACINE } 1 F\end{array}$ & $\begin{array}{l}\text { A reference core and a configuration with } \\
\text { a single rod at core center } \\
\text { Multiple rod configurations } \\
\text { Intercomparison of rod drop analysis method } \\
(\mathrm{CEA} / \text { France, ANL/US, GKAE/URSS) } \\
\text { for inserted reactivates in the range }[0.25 \$ ; 1.2 \$]\end{array}$ \\
\hline $\begin{array}{l}\text { Criticality approach } \\
\text { and neutron control } \\
\text { system issue }\end{array}$ & RACINE 1S & Simulation of neutron guides \\
\hline Sodium void & $\begin{array}{l}\text { RACINE 1A } \\
\text { RACINE 1D "Na follower" } \\
\text { RACINE 1D "B }{ }_{4} \text { C rod" }\end{array}$ & \\
\hline
\end{tabular}

This experiment was an initial approach to problems raised by large cores although the separation ratio of eigenvalues, was much lower than the desired values. The main objective of the RACINE $1 \mathrm{~S}$ program was to study the checkerboard pattern loading method selected for the start-up of Superphénix:
- making two critical configurations comprising a significant number of thinner assemblies ( $75 \%$ steel, $25 \%$ sodium).

- simulation of the "neutron guide" system implemented at Superphénix.

The radial core decoupling obtained with the heterogeneous RACINE configurations allowed to explore, at least 


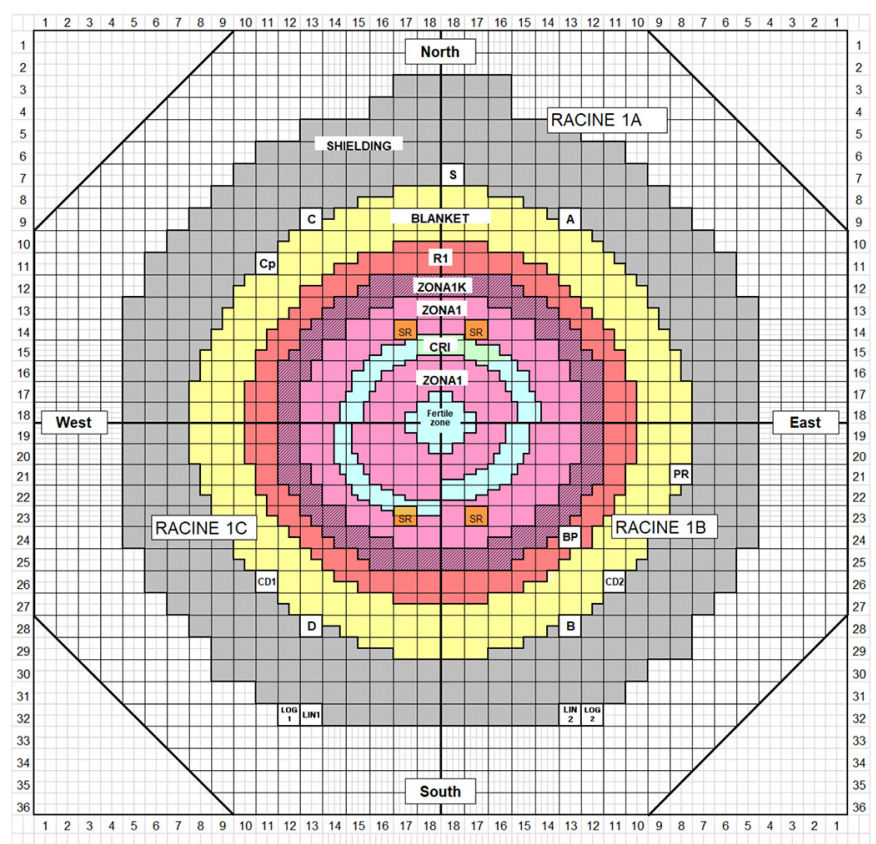

RACINE $1 \mathrm{~A}, 1 \mathrm{~B}$ and $1 \mathrm{C}$ critical configurations

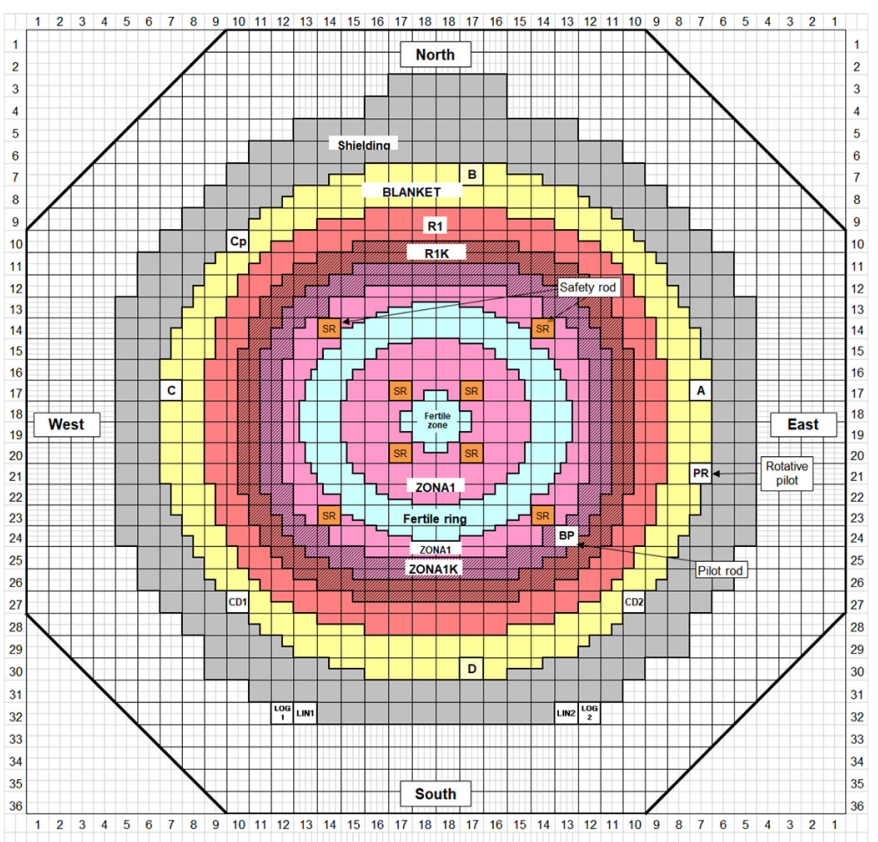

RACINE-1F critical configuration

Fig. 5. RACINE 1A, 1B, and $1 \mathrm{C}$ critical configurations. RACINE, $1 \mathrm{~F}$ critical configuration.

in part, flux tilt effects and the consequent enhancement of interaction effects that are important characteristics of large cores. Power distribution measurements, that were extensively performed, showed in particular that flux form factors (axial and radial) could be predicted with an uncertainty compatible with the $3.5 \%$ total power uncertainty sought at that time for a large power liquid metal FBR. Regarding the absorber rod interaction phenomena, single rod, and multiple rod configurations were investigated, including rod-stuck type situations. The agreement between calculations and measurements was found to be fairly constant for all configurations, including strongly asymmetric configurations.

Sodium void measurements were also performed during that period. Voided zones of different sizes and positions were considered to change the relative importance of neutron leakage and non-leakage effects. In fissile zones, reactivity effects were predicted in a consistent manner. In the internal fertile zone, they were overestimated (15-20\%) by the calculations. Neutron and $\gamma$-heating measurements demonstrated the good performances of the CEA calculation systems, even close to (and inside) singularities.

\subsection{PHÉNIX: PROFIL, TRAPU $(1974,1979]$}

The PROFIL- 1 and -2 and the TRAPU experiments $[17,23,35,47]$ were irradiation experiments performed at the French fast reactor, Phénix.

For the PROFIL-1 experiment (see Fig. 6), performed in 1974, a pin containing 46 samples, including fission products plus major and minor actinides (uranium, plutonium, and americium isotopes) was irradiated in the Phénix reactor for the first three cycles, corresponding to a total of 189.2 full-power days. The experimental pin was located in the central subassembly of the core, and in the third row of pins inside the subassembly. This location was far away from neutronic perturbations allowing favorable irradiation conditions. Following the reactor irradiation, mass spectrometry was then used, with simple or double isotopic dilution and well-characterized tracers to measure isotopic concentrations. The experimental uncertainty obtained with this method is relatively small.

The second part of the PROFIL irradiation campaign (PROFIL-2, Fig. 7) took place in 1979. During this experiment two standard pins, each containing 42 separated capsules of fission products plus major and minor actinides (uranium, plutonium, americium and neptunium isotopes), were irradiated for four cycles (the 17 through 20) in the Phénix reactor. As for PROFIL-1, chemical and mass spectrometry analyses were subsequently performed to determine the post-irradiation isotopic concentrations.

The TRAPU experiment (Fig. 8) consisted of a sixcycle irradiation (10-15) of mixed-oxide pins containing plutonium of different isotopic compositions but heavily loaded in the higher isotopes $\left({ }^{240,241,242} \mathrm{Pu}\right)$ compared to typical Phénix fuel. In the third assembly ring there are two subassemblies having a total of 10 irradiated fuel pins (5 each). Unlike other two experiments, each irradiated fuel pin has only one sample which has the same size as that of standard fuel pin. After irradiation, 20-mm-tall samples were cut from the pins (both fuel and clad) and put into a solution to determine the fuel composition by nuclide. ${ }^{148} \mathrm{Nd}$ was used as a burn-up indicator as it is a stable fission product with a small capture cross section, thereby enabling accurate determination of the number of fission reactions that took place in the sample. Again, isotopic data were obtained using mass spectrometry techniques, with simple or double isotopic dilution and well-characterized tracers. 

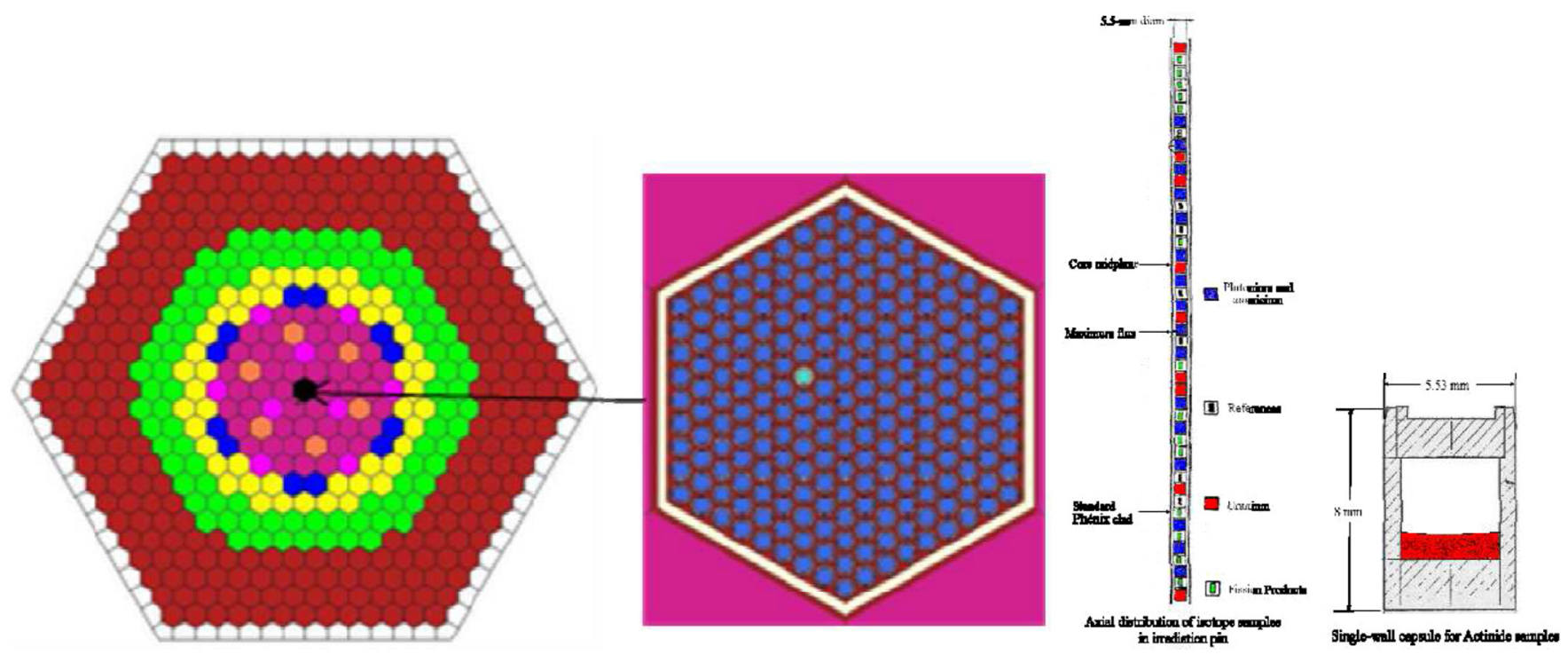

Fig. 6. PROFIL-1 irradiation experiment in the French fast reactor, Phénix.

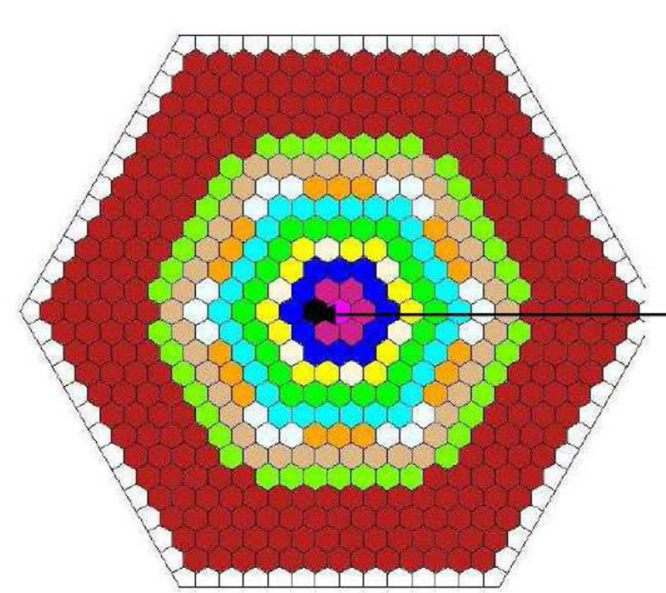

(a)

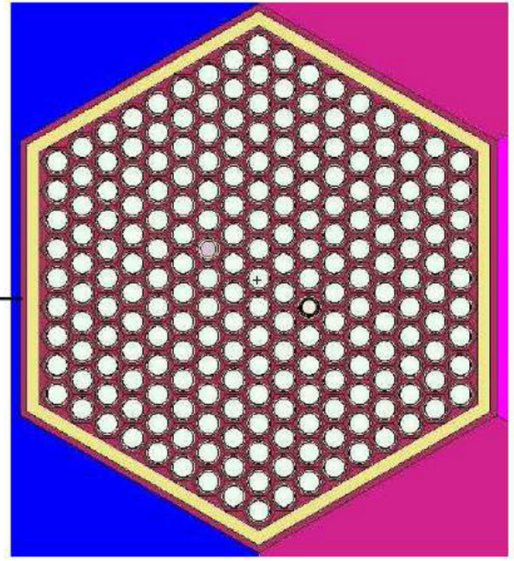

(b)

Fig. 7. PROFIL-2 irradiation experiment in the French fast reactor, Phénix. (a) Radial configuration during PROFIL-2 experiment. (b) Subassembly containing irradiated samples.

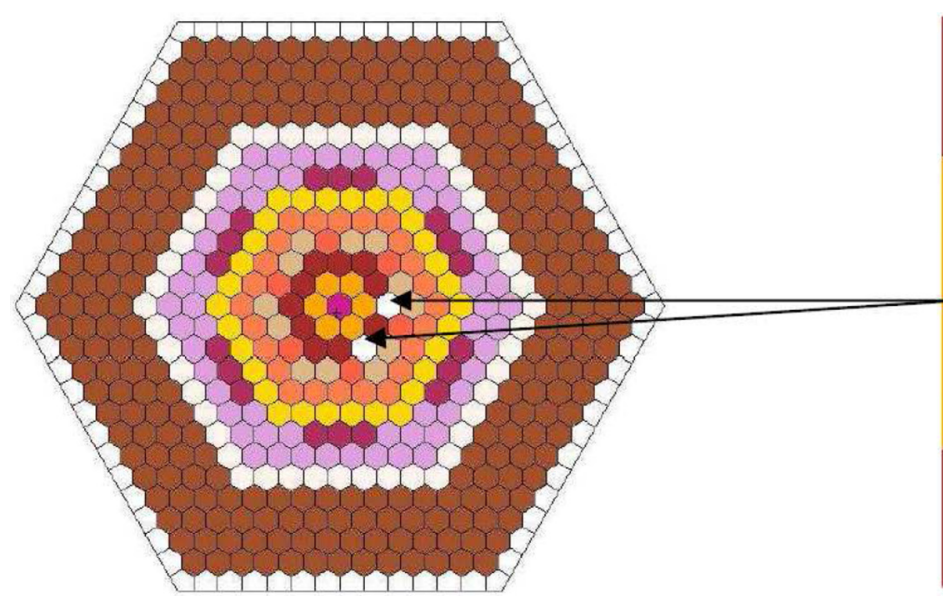

(a)

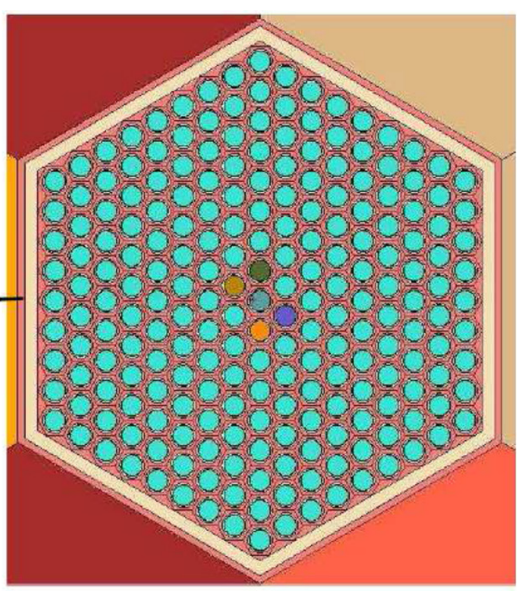

(b)

Fig. 8. Radial cross-sectional view of the TRAPU experiment. (a) Radial configuration during TRAPU experiment. (b) Subassembly containing irradiated samples. 
The PROFIL and TRAPU irradiation experiments are extremely valuable because they provide information on the transmutation rates of various isotopes. They require a significant power and irradiation time, making them very costly and for these reasons in most cases the results are still considered proprietary. Nevertheless, the PROFIL and TRAPU experiments nowadays are included in validation matrices for the most recent versions of JEFF and ENDF/ $B$ evaluated data files.

It must be mentioned that Massimo was also heavily involved in promoting and designing the irradiation experimental campaign, Super-PROFIL. This campaign was very similar to the PROFIL experiments but irradiated at the Superphénix reactor. Even though Superphénix had a short and troubled life, the irradiation took place, and the irradiated pins were then subsequently stored for the post-irradiation examination (PIE). Unfortunately, the lack of funding at CEA in the years following the Superphénix shut down prevented the PIE to ever happen, which resulted in a loss of any subsequent information expansion from that experiment.

\subsection{Superphénix start up (1985-1986)}

During the zero-power commissioning tests of large-core Liquid Metal cooled Fast Reactor (LMFR) Superphénix, the start-up experiments [18] were carried out. These experiments provided a unique knowledge on nuclear reactor behavior have been essential as well for validating the calculational accuracy of the neutronic design of the reactor. Massimo was heavily involved in both designing and analyzing these experiments. Among these of particular interest were those devoted to the critical mass, the flux distribution (core and shield), and the control rods.

Regarding the critical mass, this was a spectacular result as the critical configuration was measured at 325 fissile subassemblies in error of one subassembly of the predicted number and well within the announced uncertainty of \pm 5 subassemblies. In order to appreciate this result, one has to keep in mind that the total fissile mass of Superphénix contained more than 4 tons of plutonium.

Considerable time was devoted to control rod measurements $(24 \mathrm{~h} /$ day for 4 weeks) [22]. These tests were performed with different core configurations (see Fig. 9): first critical core, full-power core at $180^{\circ} \mathrm{C}$, and during an isothermal temperature rise from 180 to $395^{\circ} \mathrm{C}$.

This extensive program was necessary to resolve the difficulties related to spatial effects and interaction between the rods: the reactivity worth of a control rod could vary by a factor of 2.5 , depending on whether the other rods are half or fully inserted. The main measurement, methods were: Multiplication Source Method (MSM) - (method extensively studied and validated during RACINE program), rod drop from a critical configuration, balancing of two rods with the reactor critical, and temperature compensation method.

Luckily, the start-up control rod measurements were just at the lower boundary (the dangerous one) of the announced $13 \%$ uncertainty. The safety authority threatened to stop reactor operations. After first blaming the

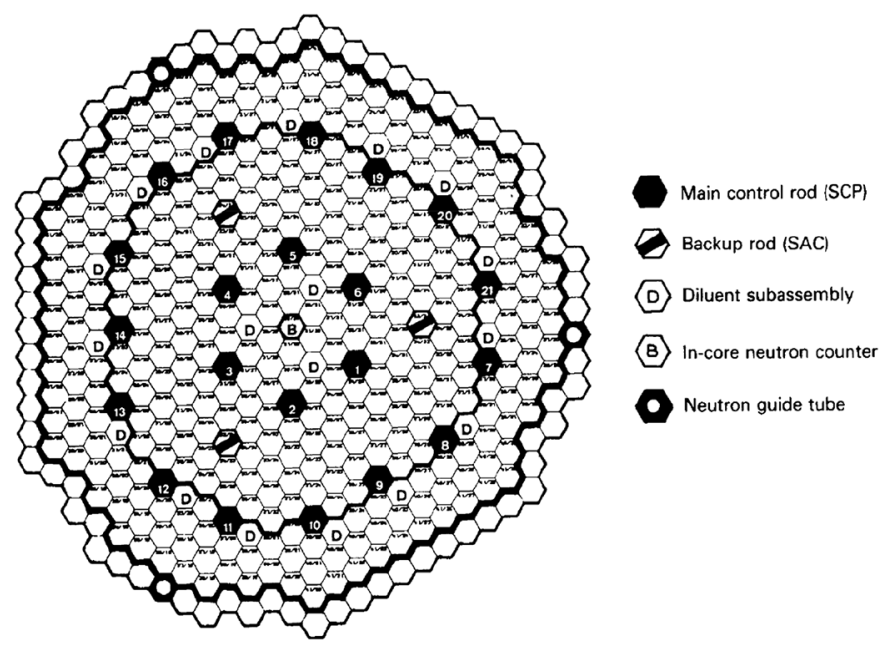

Fig. 9. View of the Superphénix reactor core; location of the control rods.

computed beta effective, with no substantiated reasoning, it was found that the problem was mostly coming from the fact that the core design team was using diffusion theory for their calculations, with crude corrective factors for transport and heterogeneity effects for the control rods. Massimo immediately diverted the BALZAC (see next section) experimental campaign, devoted to the investigation of the reactivity loss by depletion, to the study of the transport and heterogeneity effects attached to control rods. In just a few weeks, several configurations with many different heterogeneity arrangements were carried out, measured, and analyzed with new methodologies to show the capability to correctly calculate these effects. Thus, on one hand, the specific dedicated scientific and engineering problem has been solved demonstrating, on the other hand, the feasibility to build up robust and consistent procedures for calculating rod worth correction in large LMFR cores. At the same time, this would be unthinkable to do today in such a short amount of time.

\subsection{BALZAC (1984-1988)}

The objectives of the BALZAC program [19-21,24] were: - reduce the uncertainty in the reactivity swing predictions, due to the heavy isotopes.

- check the calculation tool performances on new design options associated to the Superphénix-2 project (presence of an internal storage containing irradiated subassemblies, use of $\mathrm{B}_{4} \mathrm{C}$ subassemblies separating the core from the internal storage, in the so-called BALZAC SI-1 and SI-2 configurations (see Fig. 10).

- improve the tools used for $\gamma$ heating and power deposition calculations inside dummy and absorber subassemblies.

To explain the calculation/experiment deviations observed during Superphénix start-up tests, an additional phase was quickly added to the program to obtain 

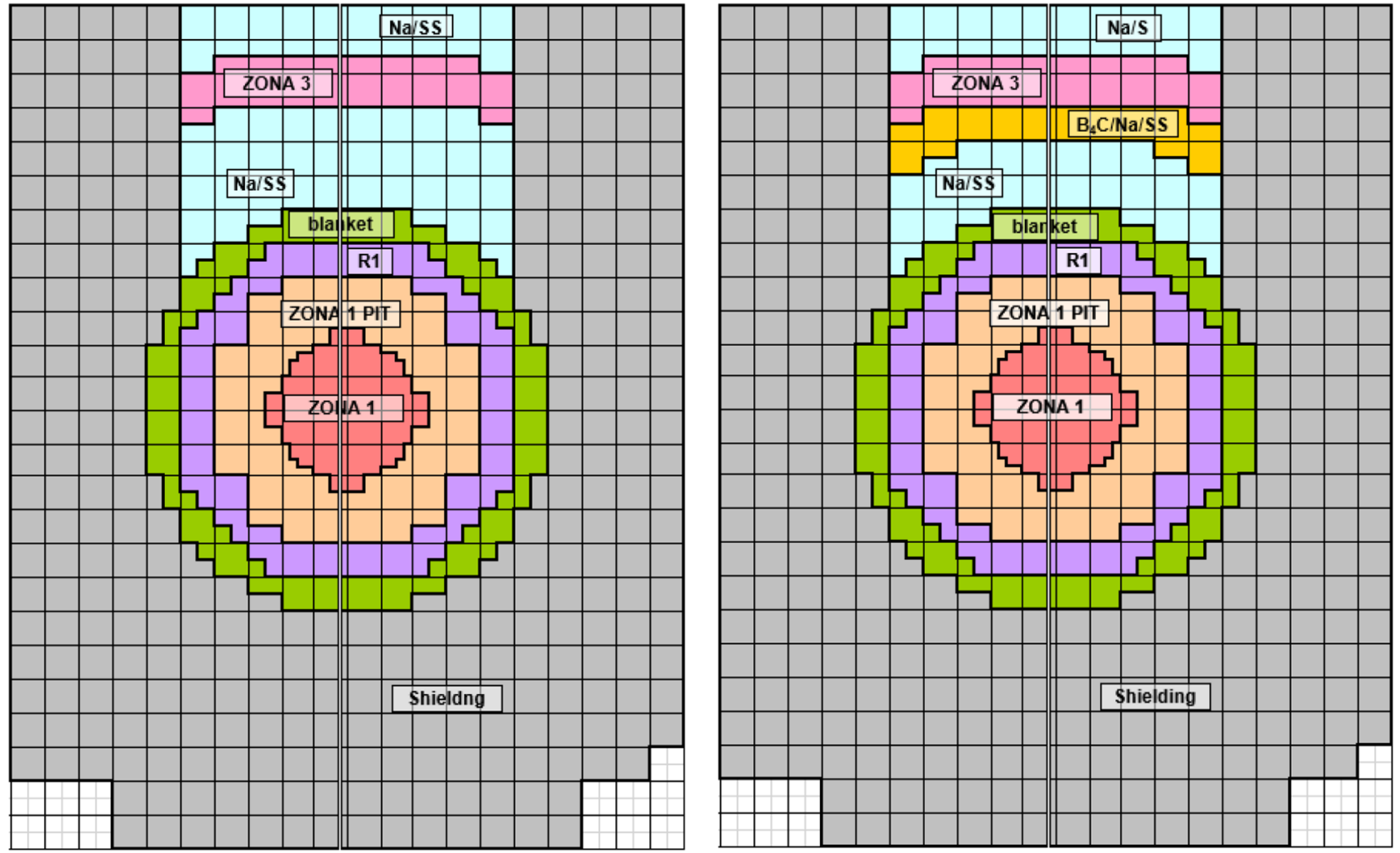

Fig. 10. Radial crosssections of BALZAC-SI1 (left) and BALZAC-SI2 (right) configurations [74].

complementary information about heterogeneity effects due to the absorber geometrical arrangement inside the control subassembly (see Fig. 11). This study showed that, when the heterogeneity of the arrangement inside the absorber rods is explicitly described and modeled, the precision of the calculations is about $2 \%$.

\subsection{CONRAD (1989-1992)}

The CONRAD program [25], led in MASURCA from 1989 to 1992 , was dedicated to strong heterogeneous cores, with emphasis on the coupling/decoupling effects and their impact on power distribution and control rods interactions. Study of the axial heterogeneous concept but with a "decoupled large core" phase (separation parameter of eigenvalues above 15) was, unfortunately, never carried out.

The first part of the CONRAD program, the CONRAD-AX experiment, was performed between June 1989 and November 1992. It formed part of the European collaboration on fast breeder reactors, specifically on the EFR project (European Fast Reactor). The aims of the program were to study the physical characteristics of the axially heterogeneous cores and to validate the methods and data for this concept. The CONRAD-AX experiments were divided into three phases, each phase being characterized by a different coupling between the upper and lower fissile regions (i.e., the thickness and composition of the internal blanket). The CONRAD-AX1 and AX2 phases included an internal fertile plate of 20 and $30 \mathrm{~cm}$, respectively, composed of uranium oxide. The fuel zone was divided into two parts of equal height (similar idea of axial heterogeneity has been used in an ASTRID conceptual design [75], where, in contrary, the fertile plate is offset downwards). Within the CONRAD-AX3 phase, the endof-cycle composition of the fertile zone was considered (i.e., with a $6 \% \mathrm{Pu}$ content).

For each phase, standard measurements were performed (reactivity, reaction rates, fission map, control rod worth). During the third phase of the experiments, particular configurations were also established to examine hypothetical accidental scenarios, including phenomena of fuel slumping and compaction. From the review of the numerous analyses performed, it was shown that there was a general good consistency in the results for all three phases, considering the wide range of configurations covered.

\subsection{BERENICE (1993-1994)}

BERENICE was an international benchmark between France, Japan and Russia, dedicated to the intercomparison of different experimental methodologies of delayed neutrons effective fraction (beta effective) measurements using two different cores:

- a uranium core, loaded with the R2 cell, quite similar to the $2 \mathrm{~B}$ core studied in 1969 , during the $\mathrm{RZ}$ program led in the early phase of the MASURCA facility. 

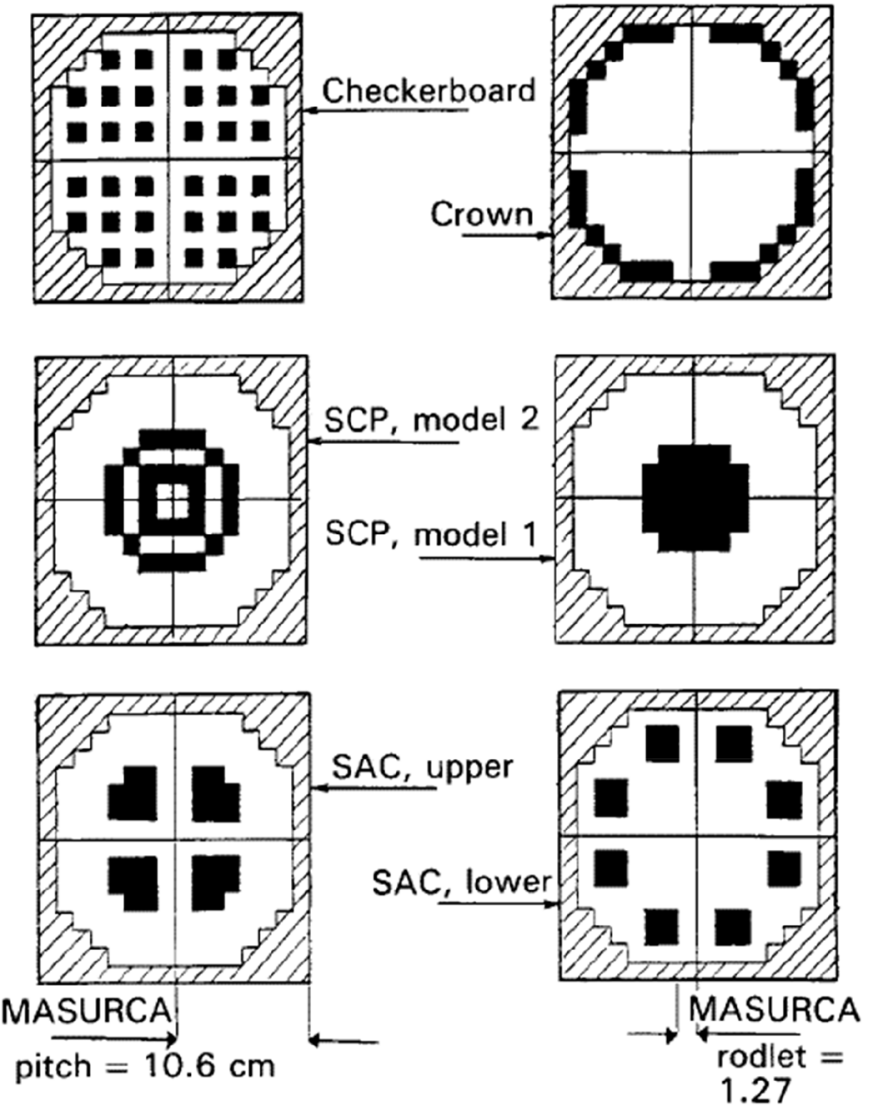

Fig. 11. Radial configurations of control rods loaded in the center of the BALZAC-1 reference core.

- a plutonium core loaded with the ZONA2 (MOX) cell.

The subsequent programs carried out in the MASURCA facility were performed in the framework of the 1991 French Law dedicated to the management of radioactive wastes, for which Massimo was heavily involved.

\subsection{CIRANO (1993-1995)}

The CIRANO program, which started in 1994, was the first of a series of three programs (CIRANO, COSMO, MUSE) directly connected with the research and development work engaged within the framework of the 1991 French Law on the management of minor actinides and long-lived fission products. CIRANO was aimed at studying plutonium-burning cores relevant for the CAPRA project.

The first phase of the program was devoted to the study of the replacement of fertile blankets by steel/sodium reflectors. The measurements were performed successively on:

- a reference core with uranium/sodium (50/50) axial and radial blankets.

- a second configuration where the radial $\mathrm{U} / \mathrm{Na}$ blanket were replaced by a stainless steel/sodium reflector $(75 \%$ $\mathrm{SS} / 25 \% \mathrm{Na}$ ).
- a third configuration where the axial U/Na blankets were also replaced by SS/Na reflectors.

The second phase addressed the in-vessel fuel assembly storage issue. It also included three different configurations:

- a reference configuration with an extended steel-sodium reflector.

- a second configuration where a row of fissile tubes was placed in the storage zone.

- a third configuration where a row of absorber tubes was added between the storage zone and the core.

The final phase of the CIRANO program consisted of loading tubes with a high-plutonium content and various plutonium isotopic composition in the central zone. The plutonium content was varied in the range of $25-48 \%$. ${ }^{240} \mathrm{Pu}$ content was varied from 8 to $33 \%$.

The large amount of CIRANO experimental data have been used to extend the validation domain of the ERANOS code system (developed by CEA after the CARNAVAL/ CCRR code system). Massimo even if he was not directly involved in this program, exploited [53] several years later the results of this campaign for studying the reflector effects that still today represent a big challenge in the design of advanced fast reactors.

\subsection{COSMO (1998-1999)}

From 1998 to 1999, the COSMO program aimed to study the local impacts on the core in the case long-lived fission products targets are irradiating in moderated subassemblies at the periphery of fast neutron reactors. The effects of various moderators, such $a^{11}{ }^{11} \mathrm{C}, \mathrm{CaH}_{2}$ and $\mathrm{ZrH}_{2}$, have been investigated. This program helped, in particular, the preparation of the ECRIX experiments loaded soon after in the Phénix reactor on 2003.

\subsection{MUSE}

As part of the studies on the transmutation of long-lived fission products in accelerator-driven systems (ADS), the MUSE program $[27,31,43,46]$ was started, with the objective of studying the physics of such a concept and the key issue of the reactivity control. Massimo was the main proposer of the MUSE program, that was the first experimental program to truly test the ADS concept proposed by Carlo Rubbia.

The initial MUSE configurations (MUSE-1, MUSE-2, MUSE-3) in the late 1990s were rather short test experiments. In particular, MUSE-3 allowed to detail the features of the pulsed neutron source used for the more extensive MUSE-4 (see Fig. 12) experiments that were carried out from 2000 to 2004 and partially funded by the European Commission as part of the fifth EURATOM framework program. Twelve partners joined this project. A reference critical core and several subcritical configurations with reactivity levels ranging from near-criticality to $-14 \$$ $(\sim-4500 \mathrm{pcm})$ were investigated. In the very last phase of the program, a configuration where sodium was partially replaced by lead was studied. Measurements were made using different external sources: the core intrinsic source 

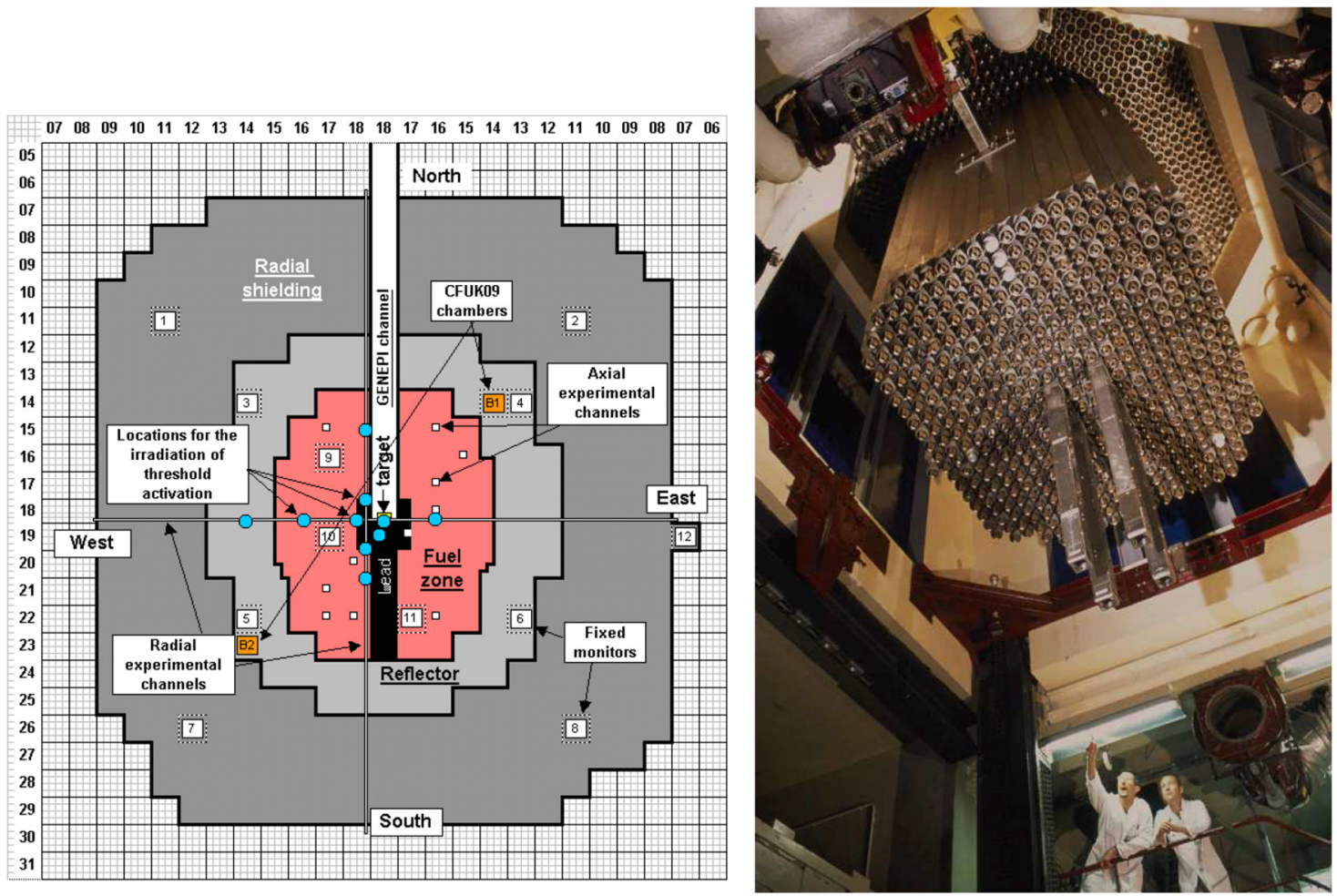

Fig. 12. The MUSE-4 Program: radical critical configuration (left), and actual MASURCA configuration (right: one can observe the GENEPI accelerator channel entering the core on the upper-left part).

due to $\mathrm{Pu}$ isotopes, ${ }^{252} \mathrm{Cf}$ sources, and 2.7 or $14 \mathrm{MeV}$ neutron sources provided by the specially designed neutron generator called GENEPI and designed by the CNRS. A large number of experimental techniques were used: the traditional rod drop/MSM method, source-jerk methods, variations of the pulsed neutron source methods, and noise methods.

A major breakthrough of the MUSE-4 program was a revised strategy for the control and the monitoring of the reactivity in power ADS. This new approach was studied within the framework of the EURATOM projects FREYA (FP7, 2011-2016) and MYRTE (H2020, 2015-2019).

\subsection{EFFTRA (1992-1998)}

The aim of the Experimental Feasibility of Targets for Transmutation (EFTTRA) collaboration between CEA (France), ECN (The Netherlands), EDF (France), Forschungszentrum Karlsruhe (FZK) (Germany), IAM, and ITU (European Commission), was to organize joint experiments for the study of materials for transmutation in reactors [32,33]. The work was focused on the transmutation of ${ }^{99} \mathrm{Tc}$ (metal), of ${ }^{129} \mathrm{I}$ (compound), and of Am (in an inert matrix). Irradiation experiments took place in parallel in the Phénix fast reactor in France, and in the high-flux thermal reactor HFR in the Netherlands. The Tc was under the form of metallic rods $(4.8 \mathrm{~mm}$ diameter) and put inside a pin with a Phénix cladding and irradiated under a thermal neutron flux in the HFR core. The EFFTRA T1 and T2 experiments demonstrated that no technical limitations were foreseen to the use of technetium in metallic form as a target for the transmutation. These experiments also paved the way to further irradiations in Phénix (the so-called ANTICORP program [76]).

\section{The "retirement" period (2001-2020)}

\subsection{MEGAPIE (1999-2006)}

MEGAPIE (MEGAwatt PIlot Experiment) [34] (see Fig. 13) was a joint initiative by Commissariat à l'Energie Atomique (CEA), France, FZK, Germany, and Paul Scherrer Institut (PSI), Switzerland, to design, build, operate, and explore liquid lead-bismuth spallation target for $1 \mathrm{MW}$ of beam power, taking advantage of the existing spallation neutron facility SINQ at PSI. This highintensity target was (and is still) under consideration for various concepts of ADS to be used in transmutation of nuclear waste and other applications worldwide. It also had the potential of increasing significantly the thermal neutron flux available at the spallation neutron source SINQ for neutron scattering. SINQ's beam power being close to $1 \mathrm{MW}$ already since the facility offered a unique opportunity to realize such experiments. Launched as a full program in 2000 , the target, filled with $920 \mathrm{~kg}$ liquid LBE, started in August 2006 and worked successfully until December 2006, delivering neutrons with an $80 \%$ higher yield. Massimo was the project leader of MEGAPIE from 1999 to 2003.

\subsection{TRADE}

The original idea of the TRiga Accelerator-Driven Experiment (TRADE) [37-42,44,50] (see Fig. 14) was 

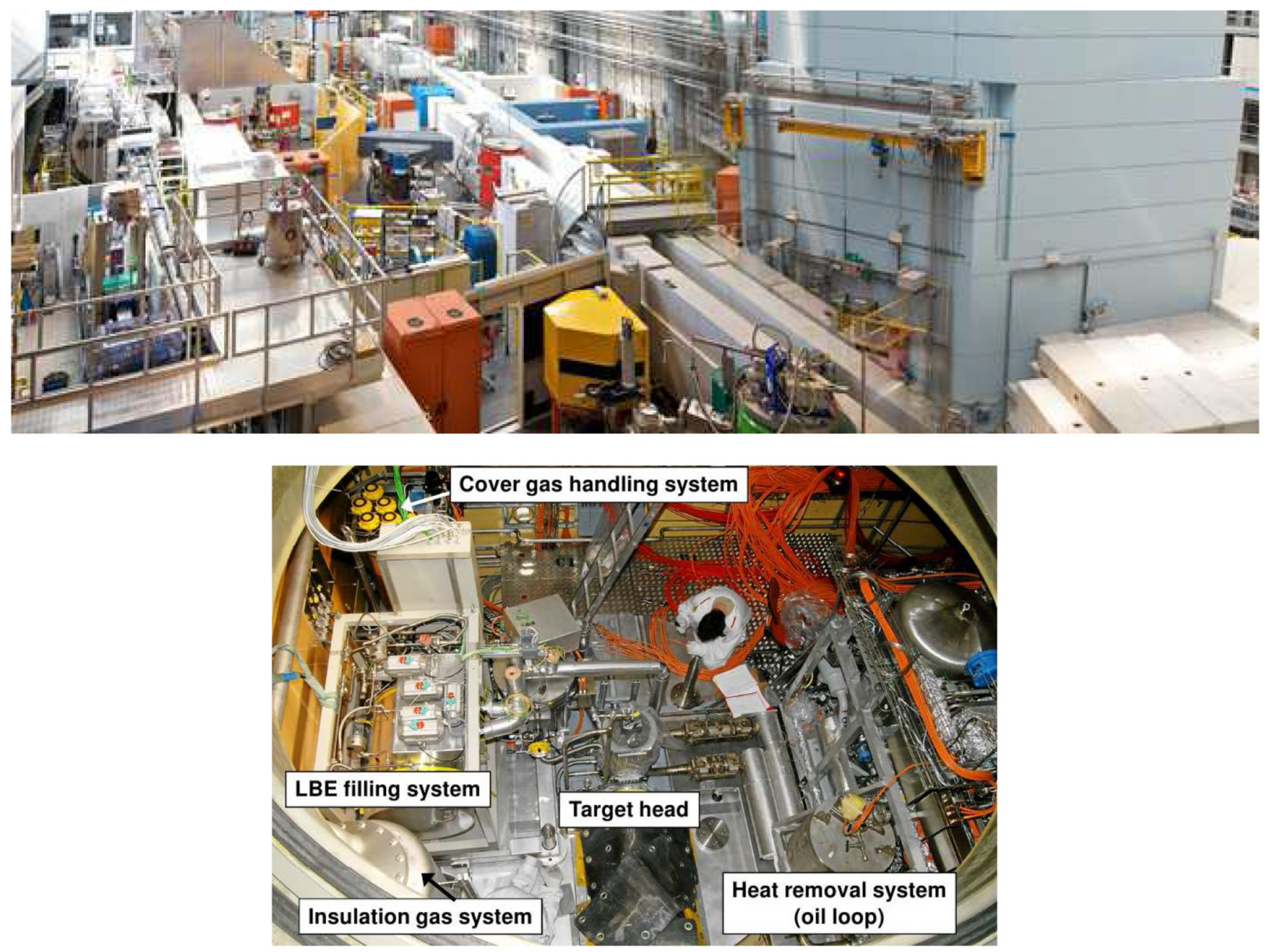

Fig. 13. SINQ facility (PSI) - MEGAPIE Project (from PSI website).

proposed by the Nobel Prize winner Carlo Rubbia. Massimo, even though he had some technical disagreement with Rubbia in the past, immediately embraced the proposal and was always very active in promoting its realization in many different organizations where he was either a consultant or an active employee. In the end, the final collaboration saw four different organizations participating to the proposed experiment: ENEA (Italy), CERN (European Nuclear Research Agency), CEA and CNRS (France), and ANL (USA). The basic idea consisted in coupling of an external proton accelerator to a target to be installed in the central channel of a low-power reactor, which was scrammed to subcriticality (TRIGA reactor at the Casaccia center). The main goal was to demonstrate the feasibility of the ADS concept. While the previous MUSE campaign looked essentially at zero-power measurements, the main purpose was to explore the dynamic behavior of the ADS including feedback effects.

As far as coupling, the experiment did not need a highneutron yield from spallation. In fact, it could have been carried out even with a neutron-per-proton production rate as low as one since an optimization in terms of efficiency or transmutation was not a requirement. The main interest of such experiment would have been to show a reliable operation of the system, from startup to nominal power level, up to shut down, in presence of thermal reactor feedback effects. The presence of control rods in the system will allow the verification of different modes of operation during fuel irradiation, and the determination and monitoring of reactivity levels with "ad-hoc" techniques.

The possibility to run the experiment at different levels of subcriticality (made possible with appropriate fuel loading patterns), allowed the experimental exploration of the transition from an external source-dominated regime to a core thermal feedback-dominated regime.The collaboration lasted few years and produced a huge amount of planning and analyses as demonstrated by the many publications produced. However, the difficulty of finding funding for buying the accelerator and the fading of interest for the ADS concept prevented the experiment from materializing.

Despite these circumstances, a huge experimental data bank was set up during the time period prior to the program termination. In particular, the TRIGA core loaded in different subcritical patterns was coupled with a pulsed neutron generator accelerating deuterium ions onto 

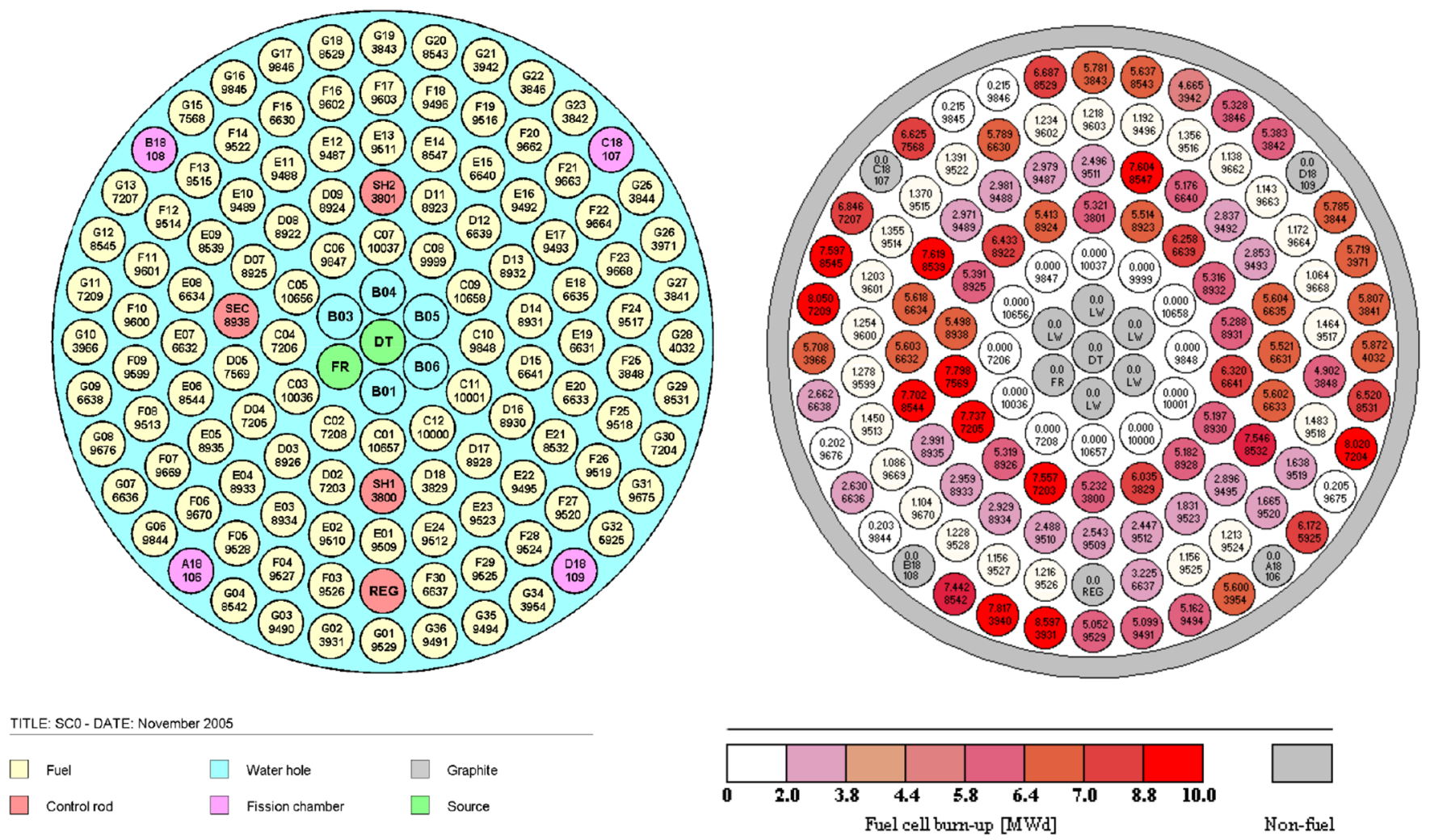

Fig. 14. TRADE subcritical configuration.

a tritium target and producing a 14.1-MeV-neutron burst with strength of $10^{8}$ neutrons/s at maximal frequency. The frequency range spanned from 1 to $150 \mathrm{~Hz}$, and the pulse duration was less than $1 \mu \mathrm{s}$. The neutron generator was located at the core center. Reactivity estimates using the so-called area-ratio and source multiplication methods were analyzed at different core locations and for three different "clean" (without control rods) core subcritical configurations, namely $\sim-500, \sim-2500$, and $\sim-5000$ pcm [77].

\subsection{MANTRA (2013-2014)}

During his stay at ANL in the early 2000, Massimo was impressed by the capability of ATLAS, an ion acceleratorbased facility, in terms of mass spectrometry. The resulting idea was to exploit this capability in an irradiation experiment. This became a reality 10 years later when he promoted the MANTRA experiment at the Advanced Test Reactor (ATR) reactor when he was a consultant at INL.

The goal of the MANTRA (Measurements of Actinide Transmutation Rates at ATR) experiment $[54,57,61,64]$ is to irradiate very pure actinide samples in the ATR and, after a given time, determine the amount of the different transmutation products. The determination of the nuclide densities before and after neutron irradiation allows inference of energy-integrated neutron cross sections.

MANTRA consists of three irradiation experiments (MANTRA A, MANTRA B and MANTRA C). In MANTRA A and B, thin $(5 \mathrm{~mm})$ and thick $(10 \mathrm{~mm})$ boron (with $70 \%$ enriched ${ }^{10} \mathrm{~B}$ ) filters were used respectively to obtain fast neutron spectra. In MANTRA C, a cadmium filter was used to attenuate the thermal part of the neutron spectrum (see Figs. 15 and 16). Two irradiation cycles for both MANTRA A and B and one irradiation cycle for MANTRA $\mathrm{C}$ were used in the ATR.

The list of actinides that have been irradiated included the following: ${ }^{232} \mathrm{Th},{ }^{233} \mathrm{U},{ }^{235} \mathrm{U},{ }^{236} \mathrm{U},{ }^{238} \mathrm{U},{ }^{237} \mathrm{~Np},{ }^{239} \mathrm{Pu}$, ${ }^{240} \mathrm{Pu},{ }^{242} \mathrm{Pu},{ }^{244} \mathrm{Pu},{ }^{241} \mathrm{Am},{ }^{243} \mathrm{Am},{ }^{244} \mathrm{Cm}$-and ${ }^{248} \mathrm{Cm}$. The list of fission products included the following: ${ }^{149} \mathrm{Sm},{ }^{153} \mathrm{Eu}$, ${ }^{133} \mathrm{Cs},{ }^{103} \mathrm{Rh},{ }^{101} \mathrm{Ru},{ }^{143} \mathrm{Nd},{ }^{145} \mathrm{Nd}$, and ${ }^{105} \mathrm{Pd}$.

Note that in the MANTRA irradiation campaign, the following isotopes have been measured in an integral experiment for the first time ever: ${ }^{244} \mathrm{Pu},{ }^{245} \mathrm{Cm},{ }^{246} \mathrm{Cm}$, ${ }^{248} \mathrm{Cm},{ }^{249} \mathrm{Bk},{ }^{250} \mathrm{Cf}$, and ${ }^{251} \mathrm{Cf}$.

\subsection{ANCESTOR: MANTRA-2 and MASSIMO (2017-today)}

The ANCESTOR program, of which Massimo was one of the two main proposers, has not yet materialized, but it is promising that the MASSIMO component could be funded soon, which would be a good recognizable tribute to him. The MANTRA-2 could follow in a second step.

The ATR and NRAD Complementary Experiments of Spectral indices, Transmutation rates, and Oscillations of Reactivity (ANCESTOR) program consists of two complementary experimental campaigns: MANTRA-2 and MASSIMO. MANTRA-2 is the second phase of the Measurements of Actinide Neutron Transmutation Rates at ATR (MANTRA) (250) irradiation experiments. It 


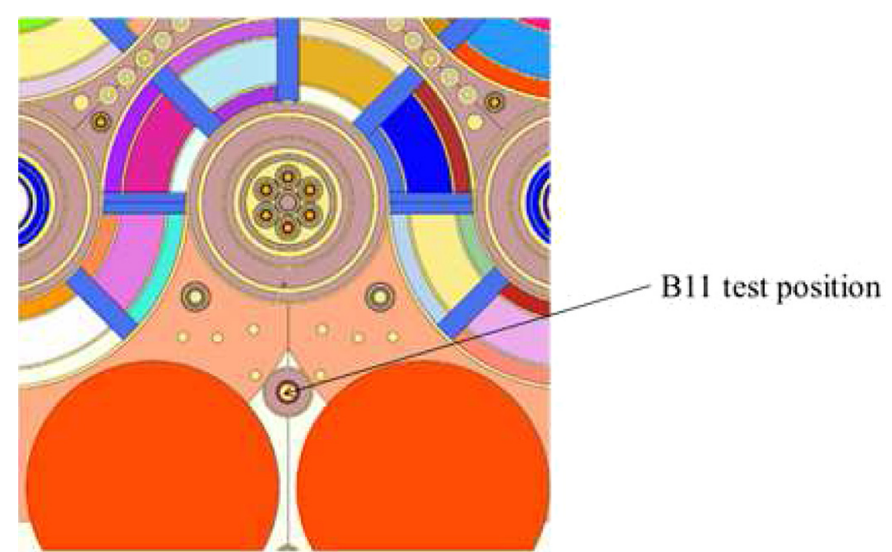

Fig. 15. Close up of the MCNP model for B11 test position for the MANTRA Cd-filtered samples irradiation.

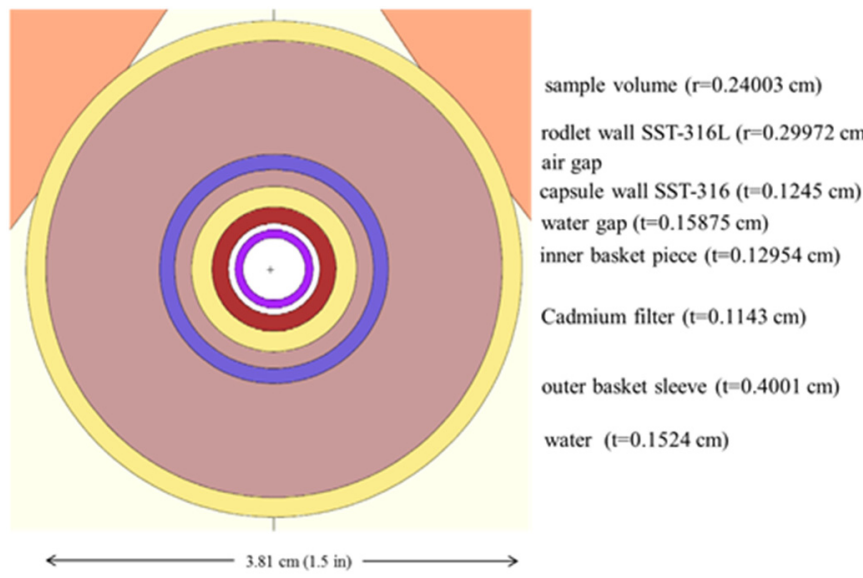

Fig. 16. MCNP model for basket and sample locations of the MANTRA Cd-filtered sample irradiation.

consists of very high-accuracy irradiation experiments within ATR using innovative experimental techniques. The Measurements in Adapted Spectra of Spectral Indices and Material Oscillation (MASSIMO) campaign will be performed in the NRAD reactor using high-accuracy techniques. The need for both experiments comes not only from the requirement to predict isotope build-up during irradiation, but also from their reactivity contribution during irradiation in case of long burnups and accurate inventories in case of temporary or deep geological storage. The MANTRA-2 irradiation experiment will provide highaccuracy data on the capture and a few $(n, 2 n)$ cross sections, while the MASSIMO spectral indices measurements will provide key data on the fission cross sections, and the MASSIMO material oscillation measurements will provide data on the competing effects of fission (if present), capture, and scattering cross sections.

The focus for the program will be the following isotopes: - major actinides $\left({ }^{235} \mathrm{U},{ }^{238} \mathrm{U},{ }^{239} \mathrm{Pu}\right)$.

- minor actinides $\left({ }^{237} \mathrm{~Np},{ }^{241} \mathrm{Am},{ }^{245} \mathrm{Cm}\right.$, etc. $)$.

- fission Products (isotopes of $\mathrm{Sm}, \mathrm{Ru}, \mathrm{Mo}, \mathrm{Pd}$, etc.).

- structural materials ( $\mathrm{Fe}, \mathrm{Cr}, \mathrm{Ni}, \mathrm{C}, \mathrm{Si}$, etc.).

- coolant materials ( $\mathrm{Na}, \mathrm{Pb}, \mathrm{Bi}, \mathrm{Li}$, and $\mathrm{Be}$ [FLiBe], etc.).

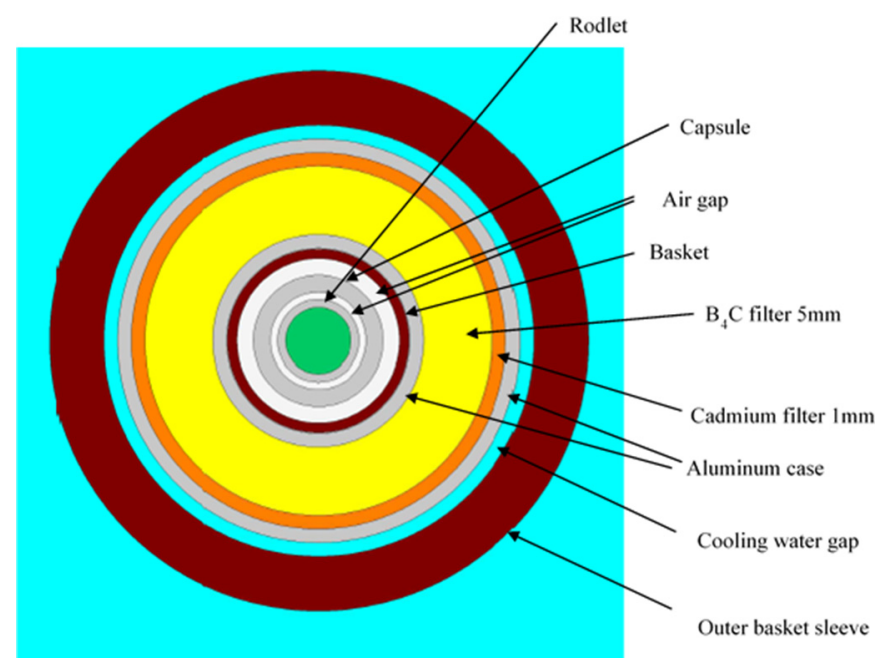

Fig. 17. Cross-section view of MANTRA-2 experiment assembly.

The MANTRA-2 (see Fig. 17) campaign is a follow-on to a previous NSUF irradiation campaign, MANTRA [61], which was completed from 2013 to 2014. The MANTRA-2 campaign improves upon some of the limitations of the original design. MANTRA-2 is expected to take 3 years to complete. The first year will be dedicated to sample preparation as well as capsule design and analysis that must be completed before insertion into ATR. The irradiations would occur in the second year. The third year would be dedicated to PIE, analytical analysis, and data assimilation.

The MASSIMO campaign will include spectral indices and material oscillation measurements, which will provide key information on the fission cross sections, as well as data on the competing effects of fission (if present), capture, and scattering cross sections. The MASSIMO spectral indices measurements will be unique because they will use a backto-back fission chamber. As long as the flux is not too anisotropic, a back-to-back fission chamber yields higher precision spectral indices measurements than those performed at most facilities, which use single isotope chambers. When using a single isotope chamber, one must place the chambers (sample isotope and reference isotope chambers) in the same position and repeat measurements, or at least get them as close to each other as possible. With the back-to-back methodology, the two different isotopes are only separated by two stainless-steel disks of only $0.15 \mathrm{~mm}$ each. Measuring the spectral indices using backto-back fission chambers is also advantageous because of the ease with which the chambers can be constructed, and the minimal electronics required. The fission foils are easily changed to allow many measurements to be made. Only a small amount of material is needed on the sample foils.

A material oscillation measurement repeatedly inserts and removes a sample material into a reactor and measures the change in the neutron profile to determine the reactivity of a sample. This allows the measurement reactivity effects of very low-worth samples with high accuracy. Using oscillation measurements allows the measurement reactivity effects of very small worth samples 


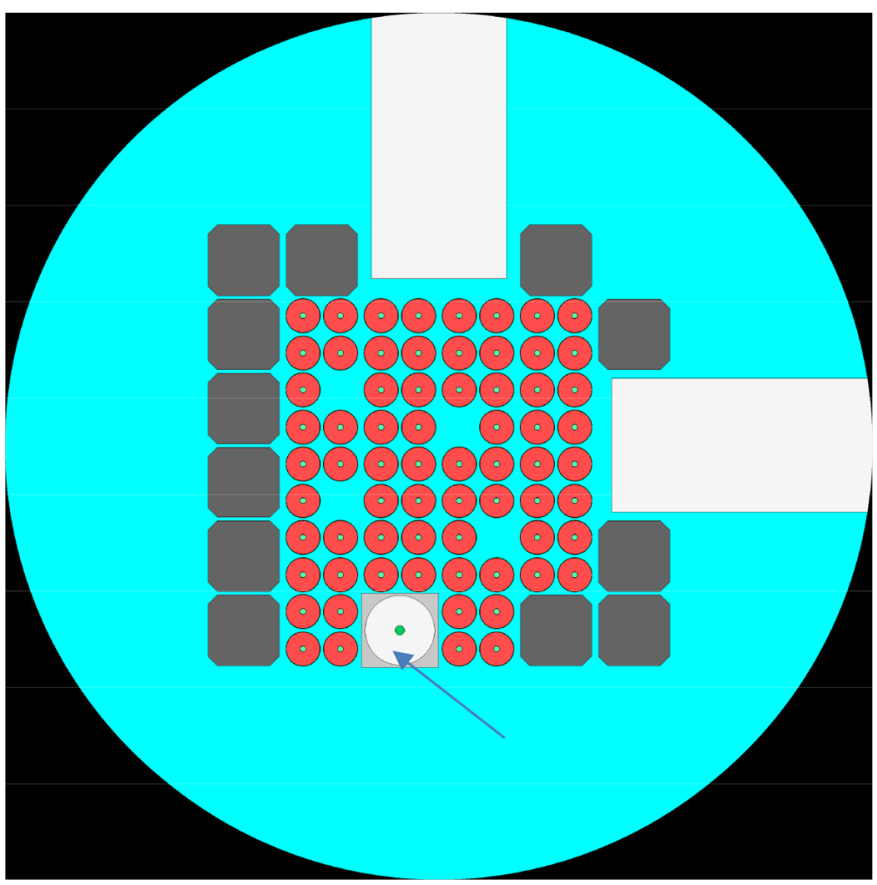

Fig. 18. NRAD reference configuration for the MASSIMO experimental campaign. The F3 position is indicated by the arrow.

on the order of at least 0.05 cents and possibly less. The MASSIMO measurements are foreseen to be carried out at $250 \mathrm{~W}$ power, ensuring, in this way, a remarkably low uncertainty $(\ll 1 \%)$.

The goal of this kind of measurement is to acquire information on the different components that contribute to the reactivity change observed in the reactor. In practice, this is obtained via calculation using exact perturbation theory because of the small change that is induced. Exact perturbation theory, contrary to direct calculations, also has the advantage of allowing quantification for each component's contribution (e.g., fission, capture, and scattering) to the reactivity variation.

Figure 18 shows a newly rearranged configuration of NRAD that enhances the reactivity effects at position F3. Figures 19 and 20 show two (of five) specific arrangements of the filters. Figure 21 illustrates the spectra for the different filters compared against the starting/reference (a typical thermal reactor spectrum): as shown, the spectra range from epithermal $(1 \mathrm{~cm} \mathrm{Cd}$ filter), typical fast reactor spectrum (Depleted uranium $+\mathrm{B}_{4} \mathrm{C}$ ), up to a very hard spectrum $\left(3 \mathrm{~mm}\right.$ of $\left.\mathrm{B}_{4} \mathrm{C}\right)$.

\section{Conclusions}

This article, as far as possible, has reported on some selected integral experiments from Massimo Salvatores's research. It testifies of the huge contribution Massimo has given to this field and how big a legacy he has left behind. While, in recent years there has been a lot of progress in advanced simulation, in Massimo words: "Experimental validation has played and will continue to play a key role

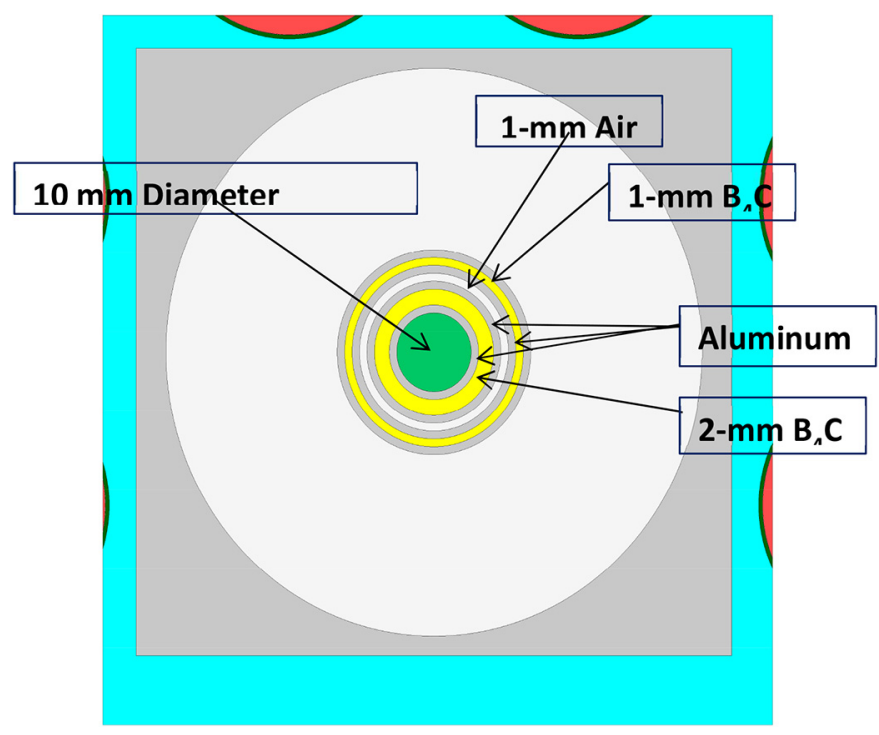

Fig. 19. Arrangement for $3-\mathrm{mm}_{4} \mathrm{C}$ filter in experimental Position F3.

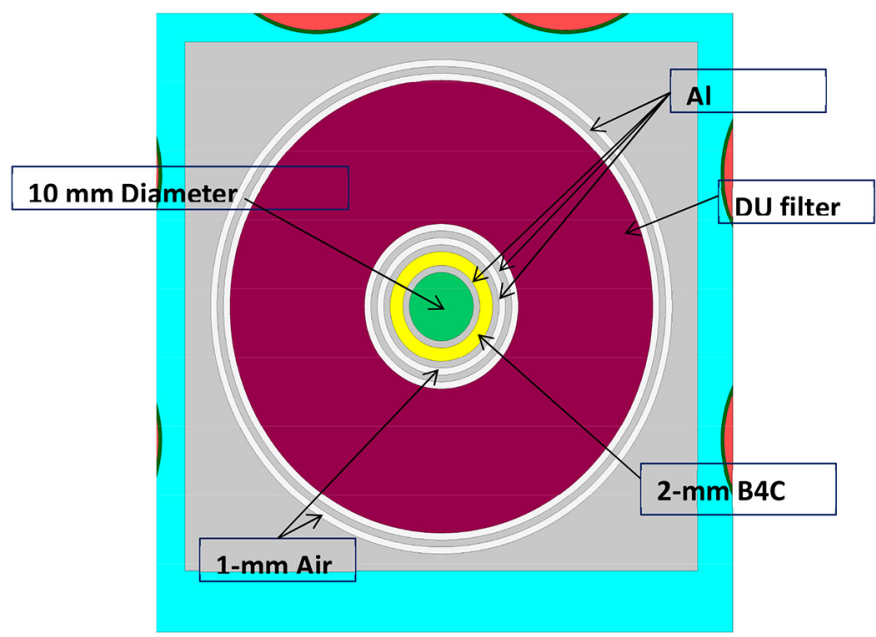

Fig. 20. Arrangement for $\mathrm{DU}+2 \mathrm{~mm} \mathrm{~B}_{4} \mathrm{C}$ filter in experimental Position F3.

both to reduce operational margins and design uncertainties, and to manage safety and licensing cases". Some statements assert that integral experiments are not needed anymore, because everything can and is simulated with a high degree of accuracy. These types of statement are still far from being realistic as we are not able to rely on simulations that have the high-fidelity level needed to support it. While it is undoubtable that different type of experiments are still needed, such as the ones providing separate effects information, the integral experiments give a necessary global confirmation. Many new projects of advanced reactors (e.g., the VTR [78]) cannot, today, count on a full-experimental program in support of it, because of the lack of funding and/or the lack of suitable experimental facilities. Instead, these programs try to rely on the large wealth of the past experimental campaigns. However, as it has been found that either essential information has been lost on these experiments, or, in 


\section{NRAD MASSIMO SPECTRA}

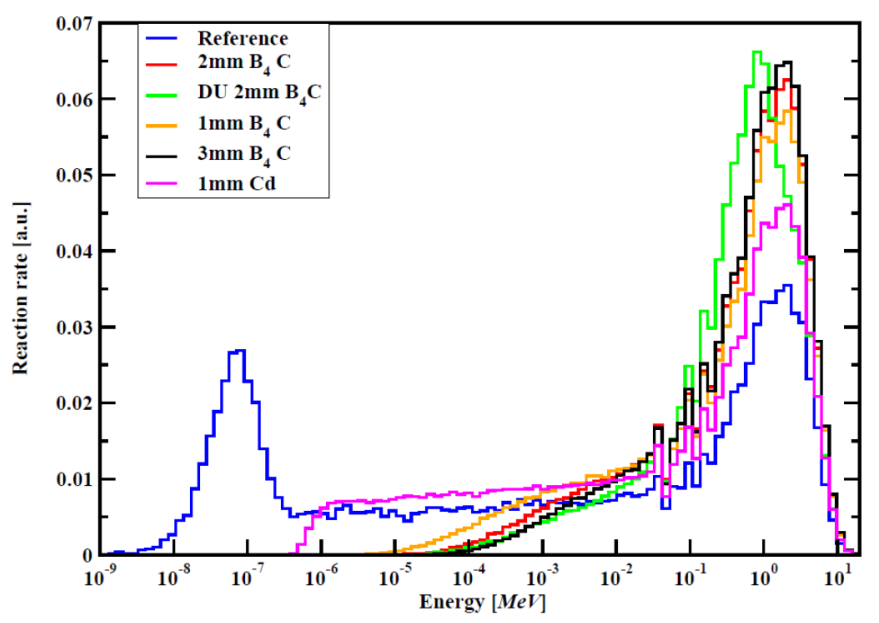

Fig. 21. Different spectra corresponding to different filters in MASSIMO experimental campaign.

most cases, this information is not relevant anymore or representative of the design of the targeted reactor. Building a new integral experimental facility capable of supporting the simulation of a large range of advanced reactors would be a welcome and needed event for the nuclear reactor community. If this happens, naming the facility after Massimo Salvatores would be the right and due tribute for honoring him.

The authors are indebted to Piero Ravetto and Mario Carta for their unvaluable contributions in providing many documents useful for reporting on many experiments where Massimo was involved.

\section{Author contribution statement}

Giuseppe Palmiotti: He had the overall responsibility of the paper and contributed to the foreword and conclusions as well to Sections 2, 3, 4, 5, 6 and 7 .

Patrick Blaise: Contributed to Sections 2, 4, 5 and 7. Frédéric Mellier: Contributed to Sections 1, 5 and 7 .

\section{References}

\section{List of Selected Publications Relevant to Integral Experiments and Their Use by $M$. Salvatores (in Chronological Order)}

1. M. Salvatores et al., ZPR-6 initial plate-rod heterogeneity measurements, Trans. Am. Nucl. Soc. 14, 18 (1971)

2. P.H. Kier, M. Salvatores, W.R. Robinson, K.D. Dance, Analysis of small sample Doppler measurements in ZPR-6 assemblies 6 and 7, Trans. Am. Nucl. Soc. 14, 844 (1971)

3. B.A. Zolotar, M. Salvatores, B.M. Bingman, E.E. Lewis, A comparative study of heterogeneity treatments for ZPR plate cells, Trans. Am. Nucl. Soc. 14, 848 (1971)
4. R.A. Karam, W.R. Robinson, M. Salvatores, Comparison of Endf/B Versions I, II, and Preliminary III, Trans. Am. Nucl. Soc. 15, 458 (1972)

5. D'Angelo, A., M. Martini, M. Salvatores, ${ }^{235} \mathrm{U}$ compact $\mathrm{Cu}$-reflected TAPIRO reactor integral experiment results and a check of some high-energy ENDF/B-III data, Trans. Am. Nucl. Soc. 17, 498 (1973)

6. D'Angelo, A., M. Martini, M. Salvatores, TAPIRO fast source reactor as a benchmark for nuclear data testing, Energia Nucleare 20, 614-621 (1973)

7. M. Salvatores, Adjustment of multigroup neutron cross sections by a correlation method, Nucl. Sci. Eng. 50, 345-353 (1973)

8. P.H. Kier, M. Salvatores, The effect of local flux distortions on the Doppler effect of small fissile samples, Nucl. Sci. Eng. 53, 479-482 (1974)

9. A. Gandini, M. Salvatores, Nuclear data and Integral Measurements Correlation for Fast reactors-Part 3: The Consistent Method, RT/FI(74)3, Comitato Nazionale per l'Energia Nucleare, Rome (1974)

10. M. Martini, G. Palmiotti, M. Salvatores, A benchmark experiment of neutron propagation in iron used to test ENDF/B cross-section data, Nucl. Sci. Eng. 56, 427 (1975)

11. J.C. Estiot, G. Palmiotti, M. Salvatores, J.P. Trapp, Interprétation des Expériences de Propagation de Neutrons dans des Mélanges Fer-Sodium avec le Formulaire PROPAN O, IAEA-OECD Meeting on the Quality of Data for Shielding Calculations, Vienna, Austria, October 1976

12. J.C. Estiot, J.P. Trapp, G. Palmiotti, M. Salvatores, Use of Integral data of the prediction of neutron propagation in ironsodium mixtures, in Fifth International Conference on Reactor Shielding, Knoxville, TN, April 1977

13. D'Angelo, A. Oliva, G. Palmiotti, M. Salvatores, S. Zero, Consistent utilization of shielding benchmark experiments, Nucl. Sci. Eng. 65, 477-491 (1978)

14. G. Palmiotti, M. Salvatores, Utilisation d'Expériences Intégrales pour la Réduction des Incertitudes Affectant les Paramétres Project dans les Calculs de Protection, in Specialist's Meeting on Nuclear Data and Benchmarks for Reactor Shielding, Paris, France, October 1980

15. M. Carta, A. De Carli, R. Martinelli, P. Moioli, G. Daguzan, M. Salvatores, J.P. Trapp, Spectrum characterization in a simulated FR blanket region via activation of threshold and continuous detectors, in Proceedings of the 4 th ASTMEURATOM Symposium on Reactor Dosimetry: Radiation Metrology Techniques, Data Bases, and Standardization, Gaithersburg, (1982) pp. 211-218

16. G. Palmiotti, M. Salvatores, Use of integral experiments in the assessment of large liquid-metal fast breeder reactor basic design parameters, Nucl. Sci. Eng. 87, 333-348 (1984)

17. J.P. Grouiller, E. Fort, F. Gibiat, P. Marimbeau, L. MartinDeidier, J. Recolin, M. Salvatores, R. Soule, P. Coulon, A. D'Angelo, J. Bouchard, M. Lucas, Comparison between calculation and experiment for the composition of heavy isotope samples irradiated in Phénix, in Proceedings of the International Symposium on Fast Breeder Reactors: Experience and Trends, 1, Lyon 407-418 (1986)

18. M. Salvatores et al., A first analysis of selected neutronics experiments at superphénix 1 start-up, in International Topical Meeting on Advances in Reactor Physics, Mathematics and Computation, Paris, France, April (1987) 
19. M. Salvatores, M. Carta, R. Soule, Power reactor and critical experiment heterogeneity effects assessment for bias factors definition, Nucl. Sci. Eng. 100, 1-15 (1988)

20. R. Soule, G. Palmiotti et al., The BALZAC Program on the MASURCA Critical Facility Main Result, in International Reactor Physics Conference, Jackson Hole, Wyoming, September 1988

21. M. Carta, G. Granget, G. Palmiotti, M. Salvatores, R. Soule, Control rod heterogeneity effects in liquid-metal fast breeder reactors: method developments and experimental validation, Nucl. Sci. Eng. 100, 269-276 (1988)

22. J.C. Gauthier, J.C. Cabrillat, G. Palmiotti, M. Salvatores, M. Giese, M. Carta, J.P. West, Measurement and predictions of control rod worth, Nucl. Sci. Eng. 106, 18-29 (1990)

23. A. D'Angelo, F. Cleri, P. Marimbeau, M. Salvatores, J.P. Grouiller, Analysis of sample and fuel pin irradiation experiments in Phénix for basic nuclear data validation, Nucl. Sci. Eng. 105, 244-255 (1990)

24. R. Soule, G. Granger, J.C. Gauthier, J.C. Cabrillat, M. Martini, G. Palmiotti, M. Salvatores, D. Calamand, A. D'Angelo, The BALZAC Program: Summary of the Comparison between the Main Calculated and Experimental Results, PHYSOR-90 International Conference on the Physics of Reactors, Marseille, France (April 23-27, 1990)

25. J.C. Cabrillat, J.C. Gauthier, M. Martini, G. Palmiotti, M. Salvatores, R. Soule, J.P. West, G. Sacre, F. Helm, A. Polch, N.T. Gulliford, The CONRAD programme: experiments and analysis for an axially heterogeneous core in the MSURCA facility, in PHYSOR-90 International Conference on the Physics of Reactors, Marseille, France April 23-27, 1990

26. C. Prunier, M. Salvatores, J.F. Babelot, J. van Geel et al., Target development and transmutation experiments in the frame of the EFTTRA European collaboration, in International Topical Conference on the Evaluation of Fuel Cycle for Future Nuclear Systems GLOBAL'95, Versailles, France, September 11-14, 1995

27. M. Salvatores, M. Martini, I. Slessarev, J.C. Cabrillat, J.P. Chauvin, P. Finck, R. Jacqmin, R. Soule, A. Tchistiakov, MUSE-1: a first experiment at MASURCA to validate the physics of sub-critical multiplying systems relevant to ADS, in Second International Conference on Accelerator-Driven Transmutation Technologies and Applications, Kalmar, Sweden, June 3-7, 1996

28. M. Salvatores, M. Martini, I. Slessarev, J.C. Cabrillat, J.P. Chauvin, P. Finck, R. Jacqmin, R. Soule, A. Tchistiakov, The neutronics of a source-driven multiplying medium and its experimental validation at MASURCA, in Physor 96 International Conference on the Physics of Reactors, Mito, Japan, September 16-20, 1996

29. M. Salvatores, Reactor physics and role of experiments, in Physor 96. International Conference on the Physics of Reactors, Mito, Japan, September 16-20, 1996

30. M. Salvatores, G. Ritter, I. Slesssarev, A. Tchistiakov, A. Zaetta, A multipurpose experimental accelerator-driven reactor: The HADRON concept, in Global'97, Yokohama, Japan, October 5-10, 1997

31. R. Soule, M. Salvatores, R. Jacqmin, M. Martini, J.F. Lebrat, P. Bertrand, U. Broccoli, V. Peluso, Validation of neutronic methods applied to the analysis of fast subcritical systems: The MUSE-2 experiments, in Global'97, Yokohama, Japan, October 5-10, 1997
32. J.F. Babelot, J.V. Geel, R. Conrad, W.M.P. Franken, H. Gruppelaar, G. Mühling, C. Prunier, M. Salvatores and M. Rome, Target development and transmutation experiments in the frame of Efftra European Collaboration, in ANS International Conference on Evaluation of Emerging Nuclear Fuel Cycle Systems, Versailles, France, September 11-14, 1995

33. J.-F. Babelot, R. Conrad, R.J.M. Konings, G. Mühling, M. Salvatores, G. Vambenepe, The EFTTRA experiment on irradiation of Am targets, J. Alloys Compd. 271-273, 606-609 (1998)

34. G.S. Bauer, M. Salvatores, G. Heusener, MEGAPIE, a 1 MW pilot experiment for a liquid metal spallation target, J. Nucl. Mater. 296, 17-33 (2001)

35. J.B. Briggs, J. Gadó, H. Hunter, I. Kodeu, M. Salvatores, E. Sartori, International integral experiments databases in support of nuclear data and code validation, J. Nucl. Sci. Technol. 39, 852-855 (2002)

36. L. Mercatali, G. Palmiotti, M. Salvatores, Analysis of PROFIL-1 irradiation experiment and related uncertainty assessment, Trans. Am. Nucl. Soc. 88, 509 (2003)

37. G. Imel, D. Naberejnev, G. Palmiotti, G. Granget, L. Mandard, Ch. Jammes, S. Andriamonje, J.C. Steckmeyer, Y. Kadi, M. Carta, R. Rosa, S. Monti, N. Burgio, A. Santagata, C. Broeders, J. Knebel, M. Salvatores, The TRADE experiment and progress, in Proceedings of the International Conference Global 2003: Atoms for Prosperity: Updating Eisenhower's Global Vision for Nuclear Energy, 1391-1397, New Orleans (2003)

38. C. Krakowiak-Aillaud, A. Bergeron, Y. Kadi, P. Agostini, M. Palomba, L. Maciocco, D. Struwe, H. Chen, X. Cheng, G. Granget, Y. Lejeail, P. Turroni, S. Monti, M. Salvatores, The TRADE solid target system design, in Proceedings of the International Conference Global 2003: Atoms for Prosperity: Updating Eisenhower's Global Vision for Nuclear Energy, New Orleans (2003), pp. 1398-1413

39. C. Rubbia, S. Monti, M. Salvatores, A. D'Angelo, G. Bignan, N. Burgio, D. Cacuci, J. Cahalan, M. Carta, P. Fougeras, G. Granget, G. Imel, C. Jammes, Y. Kadi, J. Knebel, S. Maloy, D.G. Naberejnev, H. Philibert, P. Ravetto, TRADE: A full experimental validation of the ADS concept in a European perspective, in Proceedings of the International Meeting on Nuclear Applications of Accelerator Technology: Accelerator Application in a Nuclear Renaissance, San Diego (2003), pp. $8-16$

40. P. Agostini, A. Aiello, P. Turroni, F. Pisacane, S. Monti, S. Buono, L. Maciocco, S. Maloy, Y. Lejeail, M. Salvatores, The TRADE target design and development, in Proceedings of the International Meeting on Nuclear Applications of Accelerator Technology: Accelerator Application in a Nuclear Renaissance, San Diego (2003), pp. 103-108

41. L. Picardi, C. Ronsivalle, M. Salvatores, S. Monti, L. Cinotti, N. Burgio, M. Carta, Y. Kadi, N. Meda, G. Locatelli, A. Santagata, L. Zanini and A. Herrera-Martínez, Design of the proton beam line for the TRADE experiment, in Proceedings of the International Meeting on Nuclear Applications of Accelerator Technology: Accelerator Application in a Nuclear Renaissance, San Diego (2003), pp. 138-143

42. F. Pisacane, G. Bianchini, N. Burgio, M. Carta, A. D'Angelo, A. Santagata, S. Monti, Y. Kadi, A. Herrera-Martínez, L. Zanini and M. Salvatores, Evaluation of the spallation target design characteristics for the TRADE experiment, in Proceedings of the International Meeting on Nuclear 
Applications of Accelerator Technology: Accelerator Application in a Nuclear Renaissance, San Diego (2003), pp. $425-430$

43. G. Aliberti, G. Imel, G. Palmiotti, M. Salvatores, C. Jammes, G. Perret, Dynamic analysis of source driven fast neutron systems for experimental techniques of subcritical reactivity measurement, Trans. Am. Nucl. Soc. 89, 641 (2003)

44. C. Rubbia, M. Carta, N. Burgio, C. Ciavola, A. D'Angelo, A. Dodaro, A. Festinesi, S. Monti, A. Santagata, F. Troiani, M. Salvatores, M. Delpech, Y. Kadi, S. Buono, A. Ferrari, A.H. Martínez, L. Zanini, G. Imel, Neutronic analyses of the TRADE demonstration facility, Nucl. Sci. Eng. 148, 103-123 (2004)

45. C. Rubbia, P. Agostini, M. Carta, S. Monti, M. Palomba, F. Pisacane, C. Krakowiak, M. Salvatores, Y. Kadi, A. HerreraMartínez and L. Maciocco, The TRADE experiment: status of the project and physics of the spallation target, in Proceedings of the International Conference PHYSOR 2004: The Physics of Fuel Cycles and Advanced Nuclear SystemsGlobal Developments, Chicago (2004), pp. 467-487

46. M. Carta, A. D'Angelo, V. Peluso, G. Aliberti, G. Imel, V. Kulik, G. Palmiotti, J.F. Lebrat, Y. Rugama, C. Destouches, E. González-Romero, D. Villamarín, S. Dulla F. Gabrielli, P. Ravetto, M. Salvatores, Reactivity assessment and spatial time-effects from the MUSE kinetics experiments, in Proceedings of the International Conference PHYSOR 2004: The Physics of Fuel Cycles and Advanced Nuclear Systems - Global Developments, Chicago (2004), pp. 657-669

47. L. Mercatali, G. Palmiotti, M. Salvatores, J. Tommasi, Irradiation experiment analysis for cross section validation, in Proceedings of the International Conference PHYSOR 2004: The Physics of Fuel Cycles and Advanced Nuclear Systems - Global Developments, Chicago (2004), pp. 2323-2333

48. G. Palmiotti, G. Aliberti, M. Salvatores, J. Tommasi, Integral experiments analysis for validation and improvement of minor actinide data for transmutation needs, in Proceedings of the International Conference on Nuclear Data for Science and Technology, Santa Fe (2005), pp. 1436-1441

49. M. Salvatores, The interplay of theory and experiments in reactor physics, Invited lecture as Eugene P. Wigner Reactor Physicist Award Winner, Trans. Am. Nucl. Soc. 93, 361-362 (2005)

50. M. Carta, N. Burgio, A. D'Angelo, A. Santagata, C. Petrovich, M. Schikorr, D. Beller, L.S. Felice, G. Imel, M. Salvatores, Electron versus proton accelerator driven subcritical system performance using TRIGA reactors at power, in Proceedings of the American Nuclear Society Topical Meeting on Reactor Physics PHYSOR-2006, Vancouver, Canada, (2006)

51. G. Aliberti, G. Palmiotti, M. Salvatores, Representativity studies for sodium and gas-cooled reactors, Trans. Am. Nucl. Soc. 95, 774-777 (2006)

52. M. Salvatores, G. Aliberti, G. Palmiotti, The role of differential and integral experiments to meet requirements for improved nuclear data, in ND 200\%: International Conference on Nuclear Data for Science and Technology, April 22-27, Nice, France, Vol. 2, Proceedings Pages: 883-886 Published: 2008
53. G. Palmiotti, M. Salvatores, H. Hiruta, Sensitivity analysis of experimental blanket/reflector interface effects in fast reactors for nuclear data improvement, in Proceedings of the American Nuclear Society - 4th Topical Meeting on Advances in Nuclear Fuel Management 2009, ANFM IV, 2, Head Island, South Carolina (2009), pp. 1377-1391

54. G. Youinou, G. Palmiotti, C. Mcgrath, G. Imel, M. Pau, R. Pardo, F. Kondev, M. Salvatores, MANTRA: an integral reactor physics experiment to infer actinide capture crosssections from thorium to californium with accelerator mass spectrometry, J. Korean Phys. Soc. 59, 1940-1944 (2011)

55. G. Palmiotti, M. Salvatores, Developments in sensitivity methodologies and the validation of reactor physics calculations, Sci. Technol. Nucl. Install. 2012, 529623 (2012)

56. J. Bouchard, M. Salvatores, Reactor physics development from the early sixties to yesterday: John Rowlands contribution, Trans. Am. Nucl. Soc. 107, 1171-1172 (2012)

57. R.C. Pardo, F.G. Kondev, S. Kondrashev, C. Nair, T. Palchan, R. Scott, D. Seweryniak, R. Vondrasek, M. Paul, P. Collon, C. Deibel, G. Youinou, M. Salvatores, G. Palmiotti, J. Berg, J. Fonnesbeck, G. Imel, Toward laser ablation accelerator mass spectrometry of actinides, Nucl. Instr. Methods Phys. Res. B 294, 281-286 (2013)

58. G. Palmiotti, M. Salvatores, The role of experiments and of sensitivity analysis in simulation validation strategies with emphasis on reactor physics, Ann. Nucl. Energy 52, 10-21 (2013)

59. M. Salvatores, G. Palmiotti, G. Aliberti, P. Archier, C. De Saint Jean, E. Dupont, M. Herman, M. Ishikawa, T. Ivanova, E. Ivanov, S.-J. Kim, I. Kodeli, G. Manturov, R. McKnight, S. Pelloni, C. Perfetti, A.J.M. Plompen, B.T. Rearden, D. Rochman, K. Sugino, A. Trkov, W. Wang, H. Wu, W.-S. Yang, Methods and issues for the combined use of integral experiments and covariance data: results of a NEA international collaborative study, Nucl. Data Sheets 118, 38-71 (2014)

60. G. Palmiotti, M. Salvatores, G. Aliberti, M. Herman, S.D. Hoblit, R.D. McKnight, P. Obložinský, P. Talou, G.M. Hale, H. Hiruta, T. Kawano, C.M. Mattoon, G.P.A. Nobre, A. Palumbo, M. Pigni, M.E. Rising, W.-S. Yang, A.C. Kahler, Combined use of integral experiments and covariance data, Nucl. Data Sheets 118, 596-636 (2014)

61. G. Youinou, R. Vondrasek, H. Veselka, M. Salvatores, M. Paul, R. Pardo, G. Palmiotti, T. Palchan, O. Nusair, J. Nimmagadda, C. Nair, P. Murray, T. Maddock, S. Kondrashev, F.G. Kondev, W. Jones, G. Imel, C. Glass, J. Fonnesbeck, J. Berg and W. Bauder, MANTRA: an integral reactor physics experiment to infer actinide the neutron capture cross sections of actinides and fission products in fast and epithermal spectra, Nucl. Data Sheets 119, 169-172 (2014)

62. G. Palmiotti, M. Salvatores, Role of experiment covariance in cross section adjustments (based on seminal work performed by R.D. McKnight), invited, Trans. Am. Nucl. Soc. 110, 618-621 (2014)

63. M. Salvatores, Measuring the Earth and the Sky, Invited Speech for the Plenary Session Int. Conf. Physor 2018, Q.R. Cancun, Mexico, April 22-26, 2018

64. R.C. Pardo, T. Palchan-Hazan, R. Scott, M. Paul, O. Nusair, W. Bauder, R. Vondrasek, D. Seweryniak, S. Baker, R. Talwar, P. Collon, F.G. Kondev, G. Youinou, M. Salvatores, 
G. Palmiotti, J. Berg, J. Giglio, M.T. Giglio, G. Imel, C. Nair, C.L. Jiang, Laser ablation positive-ion AMS of neutron activated actinides, Nucl. Instr. Methods Phys. Res. B 438, 172-179 (2019)

65. M. Salvatores, G. Palmiotti, Methods and approaches to provide feedback from nuclear and covariance data adjustment for improvement of nuclear data files: major findings of the NEA WPEC Subgroup 39, ND2019, Beijing, China, 2019 (to appear on EPJ Web of Conference)

66. G. Palmiotti, M. Salvatores, Revisiting the bias factor methodologies for the validation of fast test reactors, Ann. Nucl. Energy 145, 107591 (2020)

67. M. Salvatores, M. Carta, F. Orsitto, N. Burgio, V. Fabrizio, L. Falconi, F. Panza, An approach to the experimental validation of the fission multiplying blanket of hybrid fusion fission systems, to appear on Annals of Nuclear Energy

\section{Additional references}

68. C. Allardice, E.R. Trappnell, First Atomic Pile, in Astounding Science Fiction, Vol. XLVIII, 4, pp. 82-98, December 1951

69. T. Kamei, T. Yoshida, Error due to nuclear data uncertainties in the prediction of large liquid-metal fast breeder reactor core performance parameters. Nucl. Sci. Eng. 84, 83 (1983)

70. L.N. Usachev, Y. Bobkov, Planning an optimum set of microscopic experiments and evaluations to obtain a given accuracy in reactor parameter calculations, INDC CCP-19/U, International Data Committee (1972)
71. P. Blaise, E. Fort, Resonance adjustment methodology based on integral experiment analysis, Nucl. Sci. Eng. 133, 3 (1999)

72. G. Bitelli, M. Salvatores, Neutron flux and importance distribution by collision method, starting from a generalized source, Nucl. Sci. Eng. 36, 309-314 (1969)

73. G. Bignan, P. Fougeras, P. Blaise, J.P. Hudelot, F. Mellier, 2015 Chapter 18 - in Handbook of Nuclear Engineering, vol. 3, Dan Cacuci (ed.) (Springer Verlag)

74. A. Hajji, C. Coquelet-Pascal, P. Blaise, Deterministic and Monte-Carlo interpretations of the MASURCA BALZAC-SI internal storage SFR experiment and quantification of uncertainties to nuclear data, Ann. Nucl. Energy 154, 108098 (2021)

75. M.S. Chenaud, N. Devictor, G. Mignot, F. Varaine, C. Vénard, L. Martin, M. Phelip, D. Lorenzo, F. Serre, F. Bertrand, N. Alpy, M. Le Flem, P. Gavoille, R. Lavastre, P. Richard, D. Verrier, D. Schmitt, Status of the ASTRID core at the end of the pre-conceptual design phase 1, Nucl. Eng. Technol. 45, 721-730 (2013)

76. J.M. Bonnerot, V. Broudic, M. Phelip, C. Jegou, F. Varaine, X. Deschanels, M.F. Arnoux, J.L. Faugere, Transmutation in reactor and aqueous corrosion resistance of technetium metal, J. Nucl. Radiochem. Sci. 6, 287-290 (2005)

77. IAEA, Use of Low Enriched Uranium Fuel in Accelerator Driven Subcritical Systems, IAEA TECDOC SERIES, ISSN 101 14289; NO. 1821, IAEAL 17-01106, ISBN 978-92-0106217-8, (International Atomic Energy Agency, Vienna, August 2017)

78. F. Heidet, G. Youinou, T. Fei, M.A. Smith, G. Palmiotti, S. Bays, Tradeoff studies for a versatile fast spectrum test reactor. In: Proceedings of PBNC 2018, San Francisco, California, 2018

Cite this article as: Giuseppe Palmiotti, Patrick Blaise, Frédéric Mellier, Massimo Salvatores: integral experiments and their use for the validation of nuclear data and the neutronic design of advanced nuclear systems, EPJ Nuclear Sci. Technol. 7, 11 (2021) 